\title{
Thermoelectric Generator Powered Wireless Sensor Node Prototype for Nuclear Applications
}

\author{
M3CA-14-ID-BSU_-0704-0120 \\ Vivek Agarwal \\ Shelton Jacinto \\ Yanliang Zhang
}

January 2018

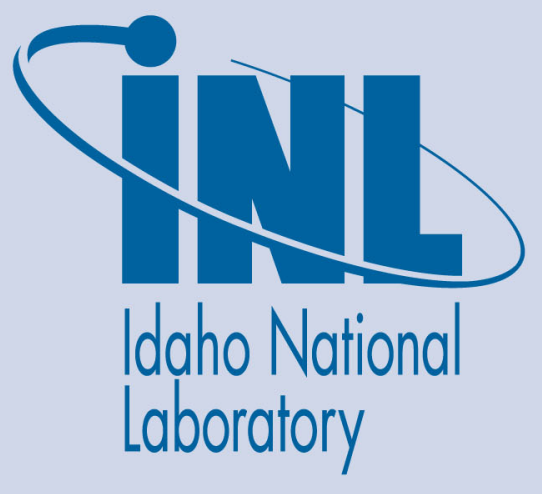

The INL is a U.S. Department of Energy National Laboratory operated by Battelle Energy Alliance 


\section{DISCLAIMER}

This information was prepared as an account of work sponsored by an agency of the U.S. Government. Neither the U.S. Government nor any agency thereof, nor any of their employees, makes any warranty, expressed or implied, or assumes any legal liability or responsibility for the accuracy, completeness, or usefulness, of any information, apparatus, product, or process disclosed, or represents that its use would not infringe privately owned rights. References herein to any specific commercial product, process, or service by trade name, trade mark, manufacturer, or otherwise, does not necessarily constitute or imply its endorsement, recommendation, or favoring by the U.S. Government or any agency thereof. The views and opinions of authors expressed herein do not necessarily state or reflect those of the U.S. Government or any agency thereof. 


\title{
Thermoelectric Generator Powered Wireless Sensor Node Prototype for Nuclear Applications
}

\author{
Vivek Agarwal ${ }^{1}$ \\ Shelton Jacinto ${ }^{2}$ \\ Yanliang Zhang ${ }^{3}$
}

January 2018
${ }^{1}$ Idaho National Laboratory
Idaho Falls, Idaho 83415
http://www.inl.gov
${ }^{2}$ Boise State University
Boise, Idaho 83725

${ }^{3}$ University of Notre Dame

Notre Dame, Indiana 46556

Prepared for the

U.S. Department of Energy

Office of Nuclear Energy

Under DOE Idaho Operations Office

Contract DE-NE0008255 
(This page intentionally left blank) 


\section{ABSTRACT}

The goal of this collaborative research between Idaho National Laboratory, University of Notre Dame, Boise State University, and University of Houston under the Nuclear Energy Enabling Technologies Program's Advanced Sensors and Instrumentation Pathway is aimed at developing efficient and reliable thermoelectric (TE) generators for self-powered wireless sensor nodes (WSNs) for nuclear applications. This power harvesting technology has crosscutting significance to all U. S. Department of Energy Office of Nuclear Energy research and development programs, as it will enable self-powered WSNs in multiple nuclear reactor designs and spent fuel storage facilities using thermal energy available in a nuclear power plant or spent fuel storage facility. This project will address the technology gap that exists in realizing truly WSNs due to the need for cables to connect to external power supplies by developing TE power harvesting devices to deliver sufficient power to drive the WSNs. The outcomes of the project will lead to significant advancement in sensor and instrumentation technologies, resulting in reduced costs, improved monitoring reliability, and therefore enhancing safety. The self-powered WSNs could support the long-term safe and economical operation of all reactor designs and fuel cycle concepts, as well as spent fuel storage and many other nuclear science and engineering applications.

Most wireless sensor network applications require operation over extended periods of time beginning with their deployment. Network lifetime is extremely critical for most applications and is one of the limiting factors for energyconstrained networks. A battery is traditionally used to power WSNs, however there is a wide range of different energy sources suitable for use depending on the application. The deployed WSN is required to last for a long time. Due to the finite amount of energy present in batteries, it is not feasible to replace batteries. Recently there has been a new surge in the area of energy harvesting where ambient energy in the environment can be utilized to prolong the lifetime of WSNs. Some of the sources of ambient energies are solar power, thermal gradient, human motion and body heat, vibrations, and ambient radio frequency energy.

This report presents the development of a TEG-powered WSN prototype that could be used in nuclear applications. Different design considerations that are important in assembling different components of a WSN were carefully taken into consideration. The designed WSN is compatible to operate with low-power generating TEG and high-power generating TEG based on application requirements. Also, to maintain appropriate power levels across different sensor node components, a direct current-to-direct current converter with maximum peak power tracking algorithm is implemented. A storage device with a real-time clock is embedded to enable local data storage and real-time time stamping. The wireless communication module selected and implemented is Zig Bee protocol. To accommodate different operating conditions and any loss of power from the TEG due to unforeseen reasons, a backup battery system is also implemented. The entire assembly was built on a 2-layer printed circuit board and tested for operation. The outcome was successful and provided enough data to validate the mathematical model developed to estimate average power consumption of a WSN under different operating conditions. 


\section{ACKNOWLEDGMENTS}

This report was made possible through funding by the U.S. Department of Energy Nuclear Energy Enabling Technologies Program. We are grateful to Suibel Schuppner at the U.S. Department of Energy and Bruce Hallbert at Idaho National Laboratory for championing this effort. We thank Nancy Lybeck for her technical input and editing of the document. 
(This page intentionally left blank) 


\section{CONTENTS}

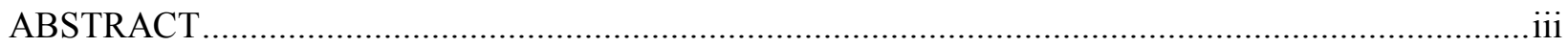

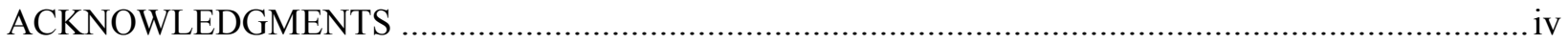

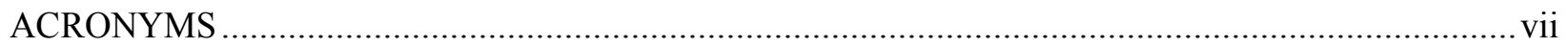

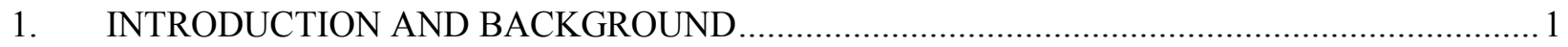

2. DESIGN OF THERMOELECTRIC GENERATOR POWERED WIRELESS SENSOR

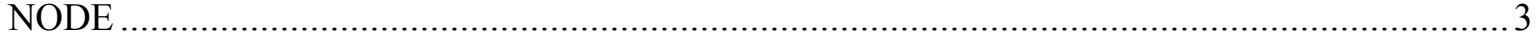

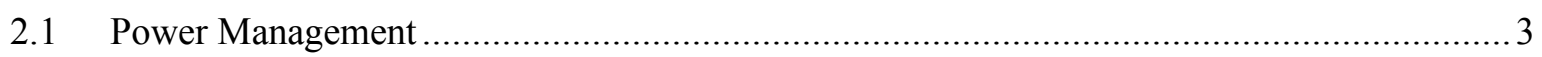

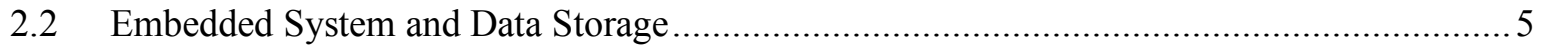

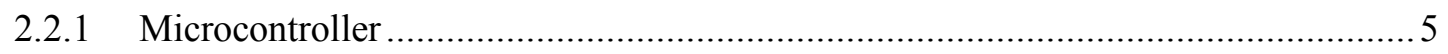

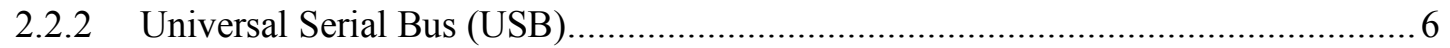

2.2.3 Real-Time Clock.................................................................................. 7

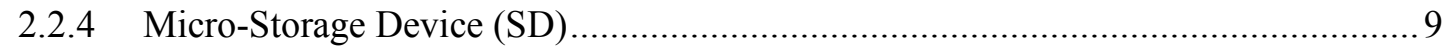

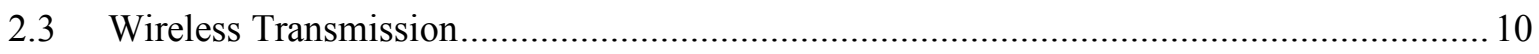

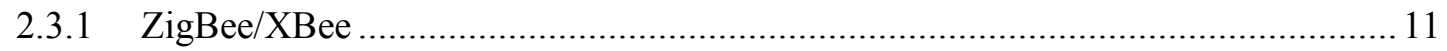

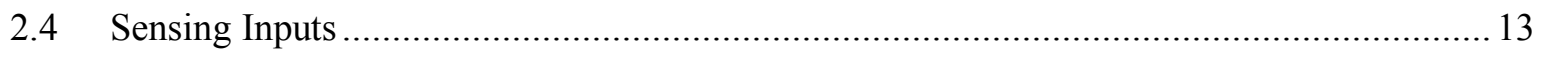

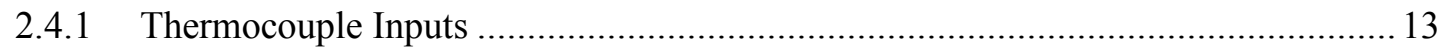

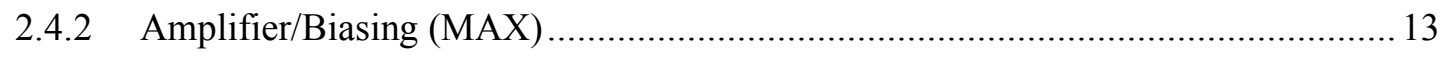

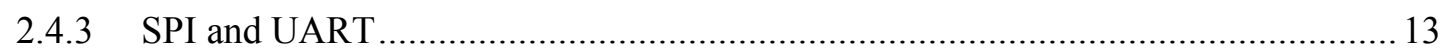

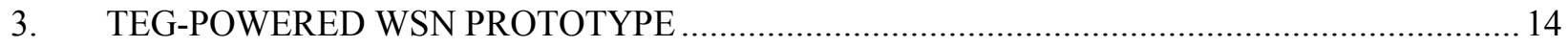

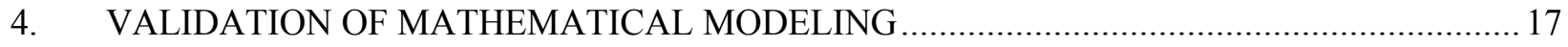

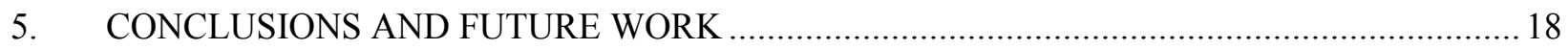

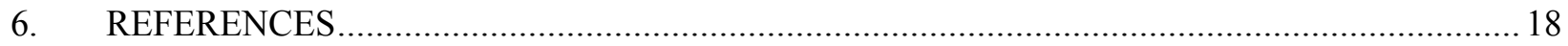

\section{FIGURES}

Figure 1. Architecture of a wireless sensor node (Culler et al. 2004) ................................................. 1

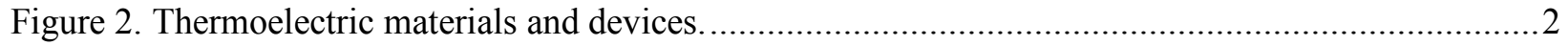

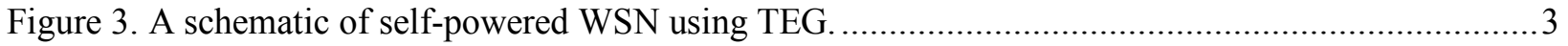

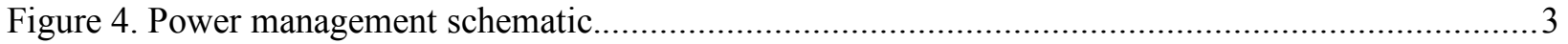

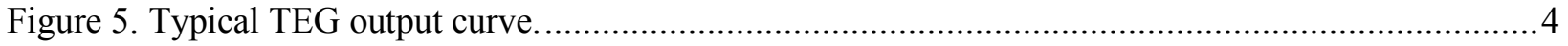

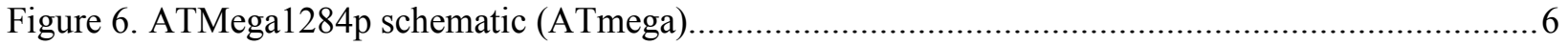

Figure 7. FTDI 232RL operational block diagram (FTDI) ......................................................... 


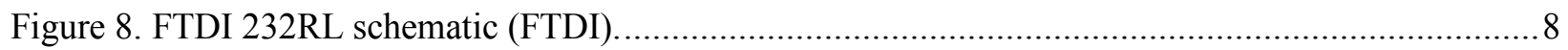

Figure 9. MAXIM DS3231 Real-Time Clock schematic (DS3231) ............................................... 8

Figure 10. MAXIM DS3231 Operational block diagram (DS3231).................................................

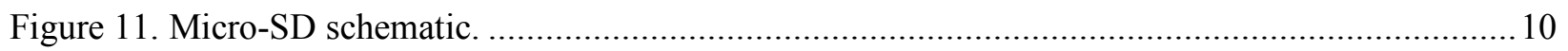

Figure 12. Flow-chart summarizing steps required to initialize Micro-SD.......................................... 11

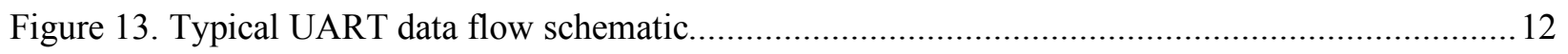

Figure 14. Initial data flow design schematic for wireless communication....................................... 13

Figure 15. Thermocouple and MAXIM MAX31856 thermocouple amplifier schematic....................... 14

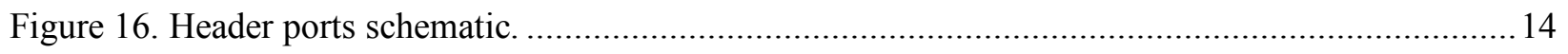

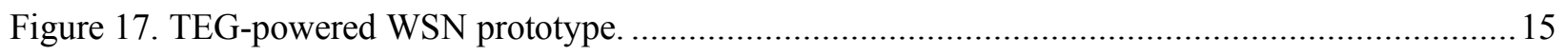

Figure 18. TEG input power versus frequency of transmission.................................................... 15

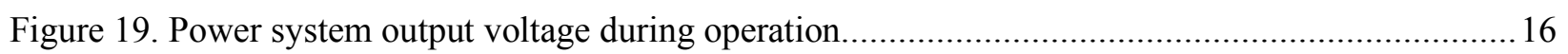

Figure 20. WSN model output based on prototype data................................................................ 18

\section{TABLES}

Table 1. ATMega324p and ATMega19284p comparison chart........................................................ 6

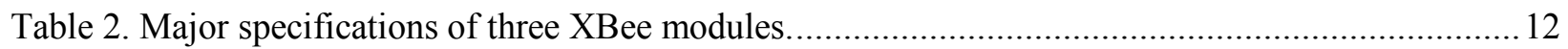

Table 3. The expected value and the variance of the energy a WSN spends in each state...................... 17 
(This page intentionally left blank) 


\section{ACRONYMS}

ADC analog-to-digital convertor

BSU Boise State University

CTS clear-to-send

DC direct current

IC integrated circuit

IEEE Institute of Electrical and Electronics Engineers

INL Idaho National Laboratory

LED light emitting diode

MPPC maximum power point control

RTS request-to-send

SD storage device

SPI Serial Peripheral Interface

TE thermoelectric

TEG thermoelectric generator

TTL Transistor-transistor logic

UH University of Houston

UND University of Notre Dame

USB Universal Serial Bus

UART Universal asynchronous receiver-transmitter

WSN wireless sensor node 
(This page intentionally left blank) 


\section{Thermoelectric Generator Powered Wireless Sensor Node Prototype for Nuclear Applications}

\section{INTRODUCTION AND BACKGROUND}

Design and technical advancements in sensing, processing, and communication capabilities of small, portable, and battery-powered devices, known as wireless sensor nodes (WSNs), have drawn extensive research attention. These WSNs, when interconnected wirelessly, regardless of topology, form a network known as a wireless sensor network and have found vast application in science, engineering, and new consumer applications (Akyildiz et al. 2002).

A WSN has an operational architecture as shown in Figure 1. From Figure 1, observe that a WSN has (1) a single energy source unit (battery and direct-current, DC, converter); (ii) an onboard embedded processing capability (microcontroller unit), (iii) an onboard sensing unit (sensors and analog-to-digital convertor, ADC) that samples the surrounding environment for sensing physical phenomenon and converts the analog signal into a digital signal, (iv) an onboard storage (memory) to temporarily store the locally processed information from the microcontroller unit, and (v) an onboard radio transceiver which wirelessly exchanges locally processed information with the base station or with other nodes in the network. Applications and energy limitations are the two key factors taken into consideration while selecting onboard components, since, WSNs are inherently resource constrained and must usually operate for extended periods of time from their limited and local energy reserves (Culler et al. 2004).

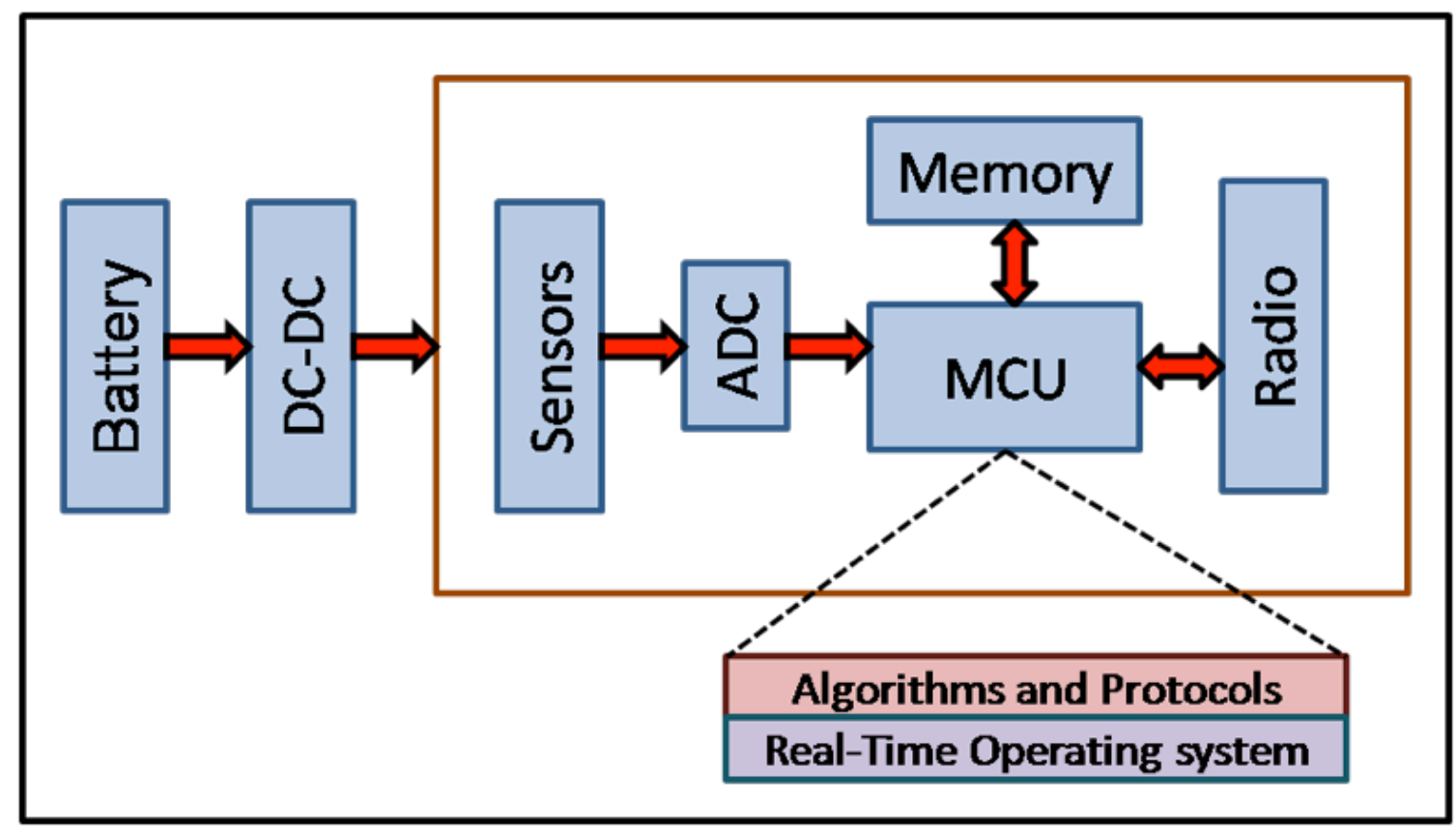

Figure 1. Architecture of a wireless sensor node (Culler et al. 2004).

Most wireless sensor network applications require operation over extended periods of time beginning with their deployment (Raghunathan et al. 2006). Network lifetime is extremely critical for most applications and is one of the limiting factors for energy-constrained networks (Dietrich and Dressler 2009). Based on these applications, wide ranges of different energy sources are suitable for powering WSNs (Rabaey et al. 2000; Beeby et al. 2007). A battery is traditionally used to power WSNs. Battery discharge behavior is nonlinear with time and depends on various factors: discharge rate, temperature, humidity, discharge/charge cycles, etc. The deployed WSN is required to last for a long time. Due to a finite amount of energy present in batteries, it is not feasible to replace them. Recently there has been a 
new surge in the area of energy harvesting where ambient energy in the environment can be utilized to prolong the lifetime of WSNs. Some of the sources of ambient energies are solar power, thermal gradients, human motion and body heat, vibration, and ambient radio-frequency energy. A detailed review of different energy harvesting techniques is presented in (Gilbert and Balouchi 2008; Clayton et al. 2012).

The application of power harvesting technologies to energize WSNs has crosscutting significance to all U. S. Department of Energy Office of Nuclear Energy research and development programs, as it will enable self-powered WSNs (ORNL 2006) in multiple nuclear reactor designs and spent fuel storage facilities. Wireless communications enable the elimination of communication wires; however, a technology gap still exists in realizing truly WSNs due to the need for external power supply cables.

The Advanced Sensors and Instrumentation Pathway under the Nuclear Energy Enabling Technologies Crosscutting Technology Development Program is supporting this research project to address this important technology gap and develop thermoelectric (TE) power harvesting devices to deliver sufficient power to drive the WSNs. Advancements in TE material efficiency over the last decade (Mehta et al. 2012; Yan et al. 2012; Poudel et al. 2008) have sparked a great deal of research in this field when compared to other applications of power harvesting technologies. With the abundance of waste heat energy available in a nuclear facility, thermoelectric generators (TEGs) are one the most promising power harvesting technologies that would benefit the nuclear industry. A collaborative team of researchers from Idaho National Laboratory (INL), Boise State University (BSU), University of Notre Dame (UND), and the University of Houston (UH) is performing this project. This partnership brings together expertise and resources encompassing three aspects critical to project success-TEGs, nuclear science, and wireless sensors.

The project goal is to develop efficient and reliable TEGs based on high-efficiency nanostructured bulk materials that directly convert heat into electricity to power WSNs for nuclear applications, as shown in Figure 2. Details on the development of TEG (Yanliang et al. 2015) and WSN (Agarwal et al. 2017) power profile are already covered in detail in previously published reports/publications, so, they won't be covered in this report. The specific objective of the project presented in this report is to show the design and development of a TEG powered WSN prototype, as shown in Figure 3, which could be used in a wireless sensor network setting to support different applications in the nuclear industry. The TEG powered WSN discussed in this report uses the TEG developed at BSU and UND to power a WSN built by integrating different commercially available electronics on a printed circuit board. The report is laid out as follows. Section 2 describes the architecture of a TEG powered WSN. Section 3 presents the prototype and its results. Section 4 describes the validation of the mathematical model develop by INL. Finally, conclusions and a potential path forward are presented in Section 5.

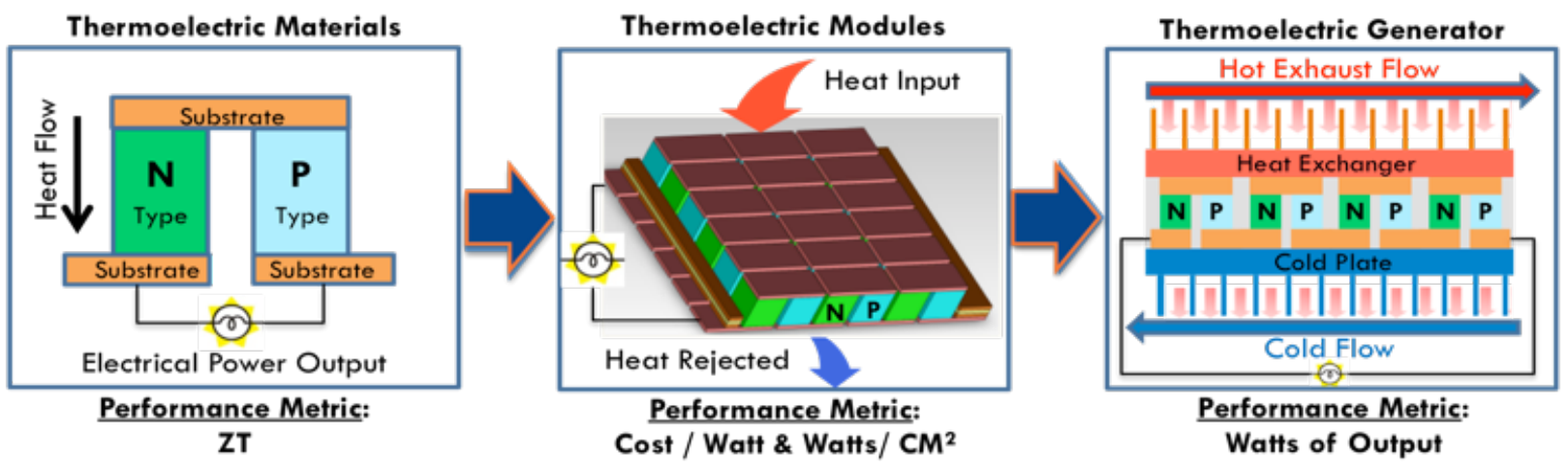

Figure 2. Thermoelectric materials and devices. 


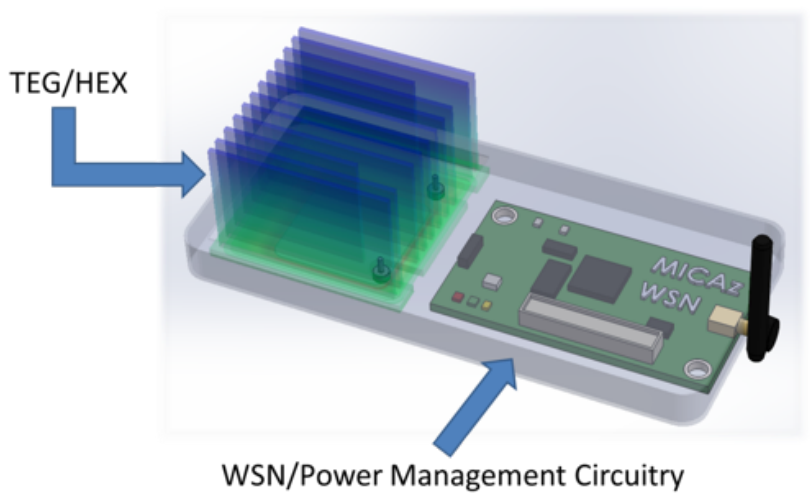

Figure 3. A schematic of self-powered WSN using TEG.

\section{DESIGN OF THERMOELECTRIC GENERATOR POWERED WIRELESS SENSOR NODE}

The design architecture of a TEG-powered WSN comprises four major elements: (1) Power management; (2) Embedded systems and data storage; (3) Wireless communication; and (4) Sensing inputs.

\subsection{Power Management}

Sustainable operation of a WSN under different operating conditions is critical, even for a selfpowered WSN. To address this challenge, in the design of the TEG-powered WSN, a DC-DC converter and a rechargeable battery storage system are deployed in the overall power management schematic design (shown in Figure 4).

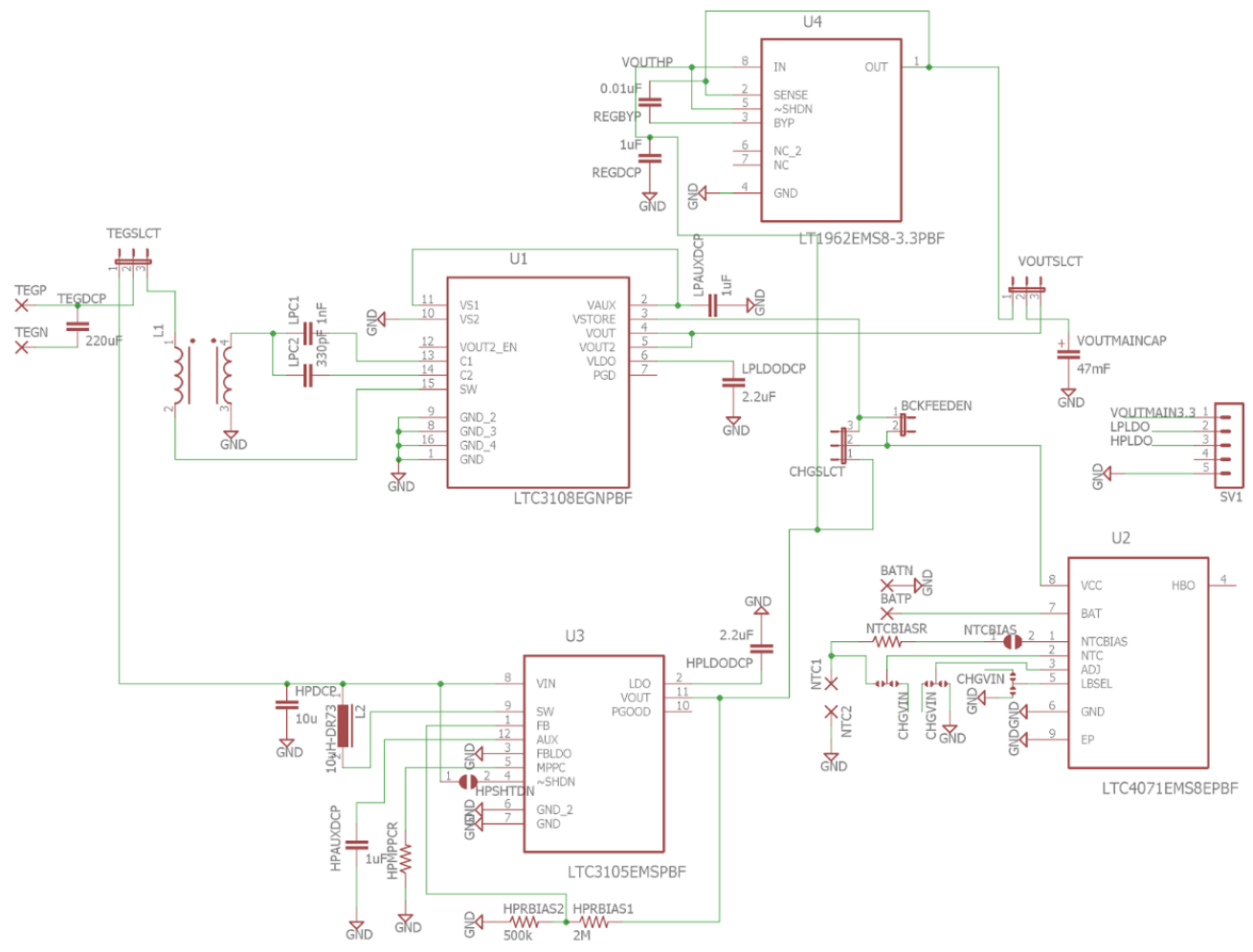

Figure 4. Power management schematic. 
A DC-DC converter is an electronic circuit or electromechanical device that converts a source of DC from one voltage level to another. The two main DC-DC converters used in the prototype design include: LTC3108 and LTC3105 (see Figure 4). These two DC-DC converters were selected because they can be configured to low-power TEGs and high-powered TEGs respectively by simply swapping the pin configuration on the circuit board.

For low-power TEGs (between $30 \mathrm{mV}$ and $250 \mathrm{mV}$ ), the LTC3108 is appropriate. It is a selfcontained, purpose-built energy harvesting integrated circuit (IC) developed by Linear Technology. The LTC3108 utilizes a flyback step-up transformer available in several turn ratios (50:1 was selected for this project) and an internal switch to boost voltage from the TEG to the appropriate level. In this project, only two outputs from the LTC3108 are utilized, VOUT (1\&2) configured to output $3.3 \mathrm{~V}$ for the microcontroller and communication system, and VSTORE which outputs $5 \mathrm{~V}$ for charging the Lithium Polymer (LiPo) storage cell. Although this IC possesses all of the necessary capabilities in terms of configurability and input range, it is limited on its output capabilities. VOUT and VSTORE are both internally current limited to just a few milliamps. Also, as the input voltage from the TEG increases, the efficiency drastically decreases. This is due to the LTC3108 shunting excess power to ground in order to maintain a stable output, resulting in poor efficiencies with higher power TEGs. The LTC3108 does support automatic maximum power point control (MPPC) which helps to maximize the power draw from the TEG.

Alternately, the LTC3105 DC-DC Boost Converter from Linear Technology is an IC best suited for use with high-powered TEGs, with voltages ranging from $300 \mathrm{mV}$ to $5 \mathrm{~V}$. The LTC3105 possesses a low startup voltage $(250 \mathrm{mV})$ and is self-sustaining afterwards. It is also internally switched, with a $10 \mathrm{mH}$ inductor configured in a standard boost setup. While the LTC3105 can operate at a variety of output voltages (configurable with bias resistors), it is set to output $5 \mathrm{~V}$ which will then be regulated down to $3.3 \mathrm{~V}$ for the microcontroller and communication system. The $5 \mathrm{~V}$ output is due to the requirement for the LiPo management IC to have a higher input voltage than the end charge voltage of the backup cell. Otherwise, it would be incapable of properly charging the lithium battery. The maximum current of the LTC3105 also varies according to input voltage but will operate in the range of 100-200 mA range with operating at efficiencies of $>50 \%$. The LTC3105 also supports MPPC.

The importance of MPPC in both DC-DC converters, LTC3108 and LTC3105 is related to power output of the TEG as shown in shown in Figure 5. TEGs have the advantage of producing low voltage outputs at relatively high currents. These high currents can then be stepped up and utilized in more

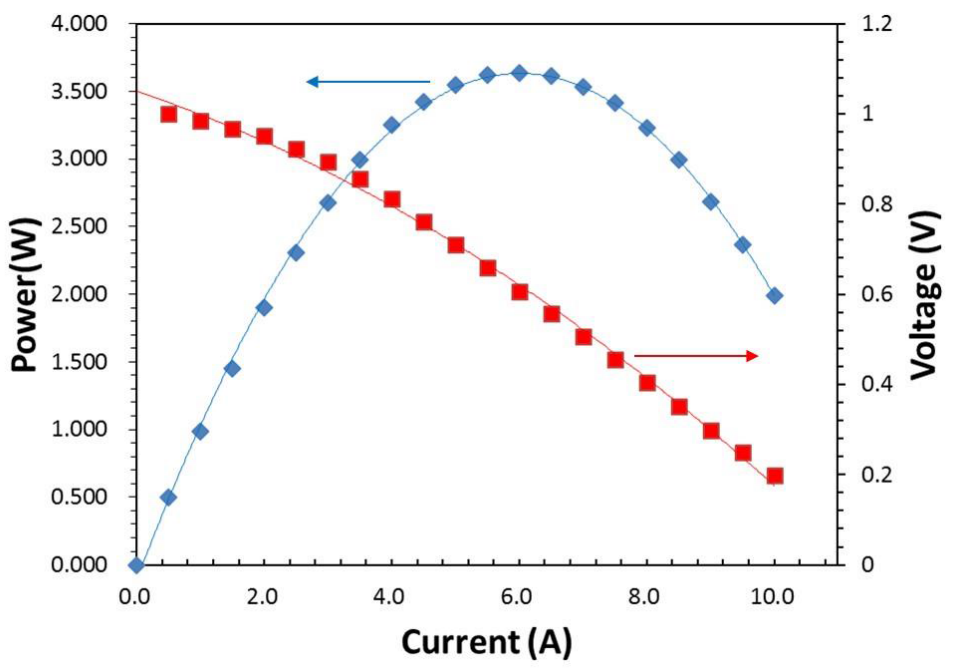

Figure 5. Typical TEG output curve. 
applications; however, the amount of current drawn from the TEG will dictate its overall power output. When high current is draw, it reduces the output voltage, resulting in a drop-in power output. The MPPC system in both the LTC3108 and LTC3105 will allow each IC to maximize the amount of power from the TEG, increasing output, efficiency, and decreasing the time needed between transmissions.

To regulate the $5 \mathrm{~V}$ produced by the LTC3105 down to the $3.3 \mathrm{~V}$ that is used by the rest of the WSN, the LT1962 low dropout regulator is implemented. It is a configurable linear regulator that will limit the voltage on its output to the necessary $3.3 \mathrm{~V}$. This IC will also allow the power manager to be back-fed by external means (through universal serial bus, USB) and allow for continuous transmission when needed.

An important component in the power management system is the output storage capacitor. As the expected power required from the communication system during transmission is more than either IC will be capable of producing continuously, a large storage capacitor is connected to the main $3.3 \mathrm{~V}$ output. This will allow the system to charge the storage capacitor to $3.3 \mathrm{~V}$ and maintain its voltage at that point. While transmitting, energy will be drawn from this capacitor to power the system during operation. Once complete, the current draw will drop, allowing the power manager ICs to recharge the capacitor back to the $3.3 \mathrm{~V}$ steady state.

The last component in the power management is the battery backup. In order for the communication system to continue functioning in the event of power loss, a backup system is implemented. For high energy density and appropriate output voltage, a $5000 \mathrm{mAh} \mathrm{LiPo} \mathrm{cell} \mathrm{is} \mathrm{selected} \mathrm{to} \mathrm{be} \mathrm{the} \mathrm{main} \mathrm{backup}$ cell. Due to the nature of lithium cells, a dedicated battery management IC is mandatory to constantly charge and maintain the cell at the appropriate levels. The LTC4071 is chosen due to its self-contained nature and high configurability. This IC has the ability to set the cell charge cutoff voltage $(4.0 \mathrm{~V}, 4.1 \mathrm{~V}$, or $4.2 \mathrm{~V})$, low battery disconnects $(2.7 \mathrm{~V}$ or $3.2 \mathrm{~V})$, and charge current (maximum of $50 \mathrm{~mA})$. Upon overdischarge the IC will auto-disconnect it from the rest of the board, drawing $<1 n$ A to maintain this disconnect. It also has the provision for negative temperature coefficient probe thermal monitoring. This allows the LTC4071 to adjust its cell float voltage based on the cell temperature, lowering the output at higher temperatures to maintain cell life and stability.

\subsection{Embedded System and Data Storage}

\subsubsection{Microcontroller}

The microcontroller chosen for this project is a more powerful revision of the ATMega324p which was used initially in the Advanced Energy Lab for a rough prototype of the sensor node. The microcontroller in use for the final design will be the ATMega1284p, which offers similar performance and input/output ports but also make accessible a greater amount of Rapid Access Memory (RAM) and system memory. The increased memory is important to this project due to the size and complexity of code in use. Initial findings revealed that the original microcontroller that was used, the ATMega324p, ran out of room to run the program as compiled and also ran out of room to store local data. Table 1 summarizes feature comparison between ATMega324p and ATMega1284p microcontrollers.

The implementation of the microcontroller is shown in Figure 6. The standard components necessary to support microcontroller operation are implemented in the design. These include, a precision external oscillator controlling the operating frequency at a steady value of $8 \mathrm{MHz}$; two status light emitting diodes (LEDs) connected directly to the microcontroller to provide visual signal to the end-user in case of fault or hard interrupt; and a RESET button to enable system reset, if required. 
Table 1. ATMega324p and ATMega19284p comparison chart.

\begin{tabular}{|c|c|c|c|c|c|c|c|c|c|c|c|c|c|c|}
\hline Name & SRAM & ROM & EEPROM & IO Pins & Speed & ADC-Bits & PWM & $\begin{array}{c}\text { Minimum } \\
\text { Supply } \\
\text { Voltage }\end{array}$ & $\begin{array}{c}\text { Timers/ } \\
\text { Counters }\end{array}$ & SPI & I2C/TWI & UART & $\begin{array}{c}\text { ADC } \\
\text { Channel }\end{array}$ & $\begin{array}{c}\text { External } \\
\text { Interrupts }\end{array}$ \\
\hline $\begin{array}{c}\text { AVR } \\
\text { ATmega32 } \\
4 p\end{array}$ & $2 \mathrm{~KB}$ & $32 \mathrm{~KB}$ & $1024 \mathrm{~B}$ & 32 & $\begin{array}{c}20 \\
\mathrm{MHz}\end{array}$ & $\begin{array}{c}10-\mathrm{Bit} \\
\mathrm{AVR}\end{array}$ & 6 & $1.8 \mathrm{~V}$ & 3 & 3 & 1 & 2 & 8 \\
\hline $\begin{array}{c}\text { ATmega } \\
1284 \mathrm{p}\end{array}$ & $16 \mathrm{~KB}$ & $128 \mathrm{~KB}$ & $4096 \mathrm{~B}$ & 32 & $\begin{array}{c}20 \\
\mathrm{MHz}\end{array}$ & $10-\mathrm{bit}$ & 6 & $1.8 \mathrm{~V}$ & 3 & 3 & 1 & 2 & 8 & 32 \\
\hline
\end{tabular}

\section{ATMEGA1284}

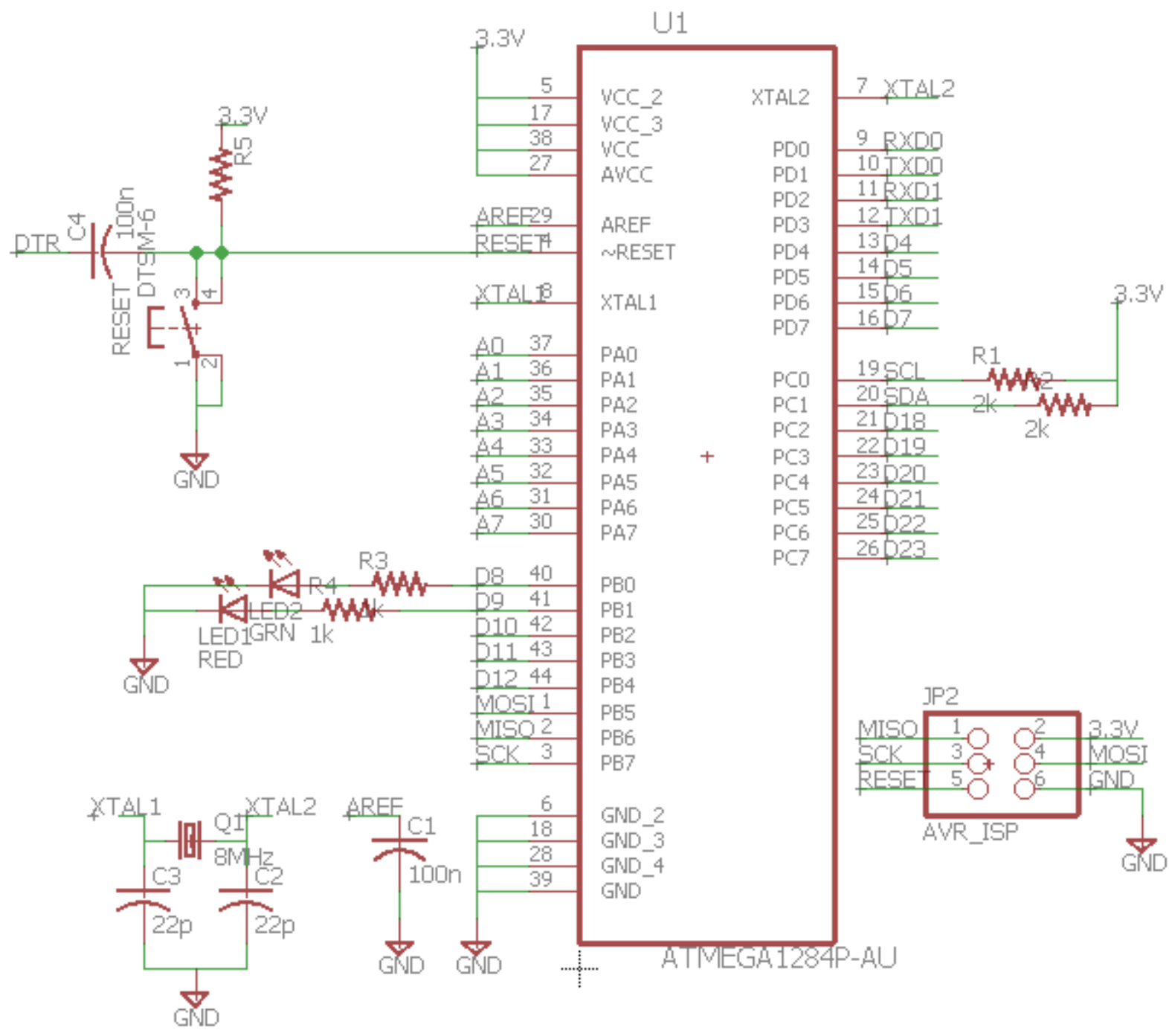

Figure 6. ATMega1284p schematic (ATmega).

\subsubsection{Universal Serial Bus (USB)}

The chip being used to handle the USB to Universal asynchronous receiver-transmitter (UART) interfacing is the Future Technology Device International (FTDI) Ltd 232RL. The FTDI 232RL is the leading all-in-one package to handle USB to UART data transfers in nearly all devices where a USB port 
is present. The featured problem solved by the 232RL is that the entire USB protocol is handled, in hardware, on the chip, and that no specific USB firmware is required. Since both the Transistor-transistor logic (TTL) conversion and data transmission are handled on-chip, the data rates achievable by the 232RL are extremely high. The maximum data rate is $3 \mathrm{Mbaud}$ or, 3 million bits per second ( $3 \mathrm{Mb} / \mathrm{s})$, with an error rate near $0 \%$. As shown by the block diagram in Figure 7, there is direct access for both USB as well as for a typical FTDI TTL cable, with pass through possible for a USB cable with a built-in FTDI chip. The built-in First-in, First-out ring buffer allows for the high data-rates which may be used if transmissions through the microcontroller are set at their maximum set point.

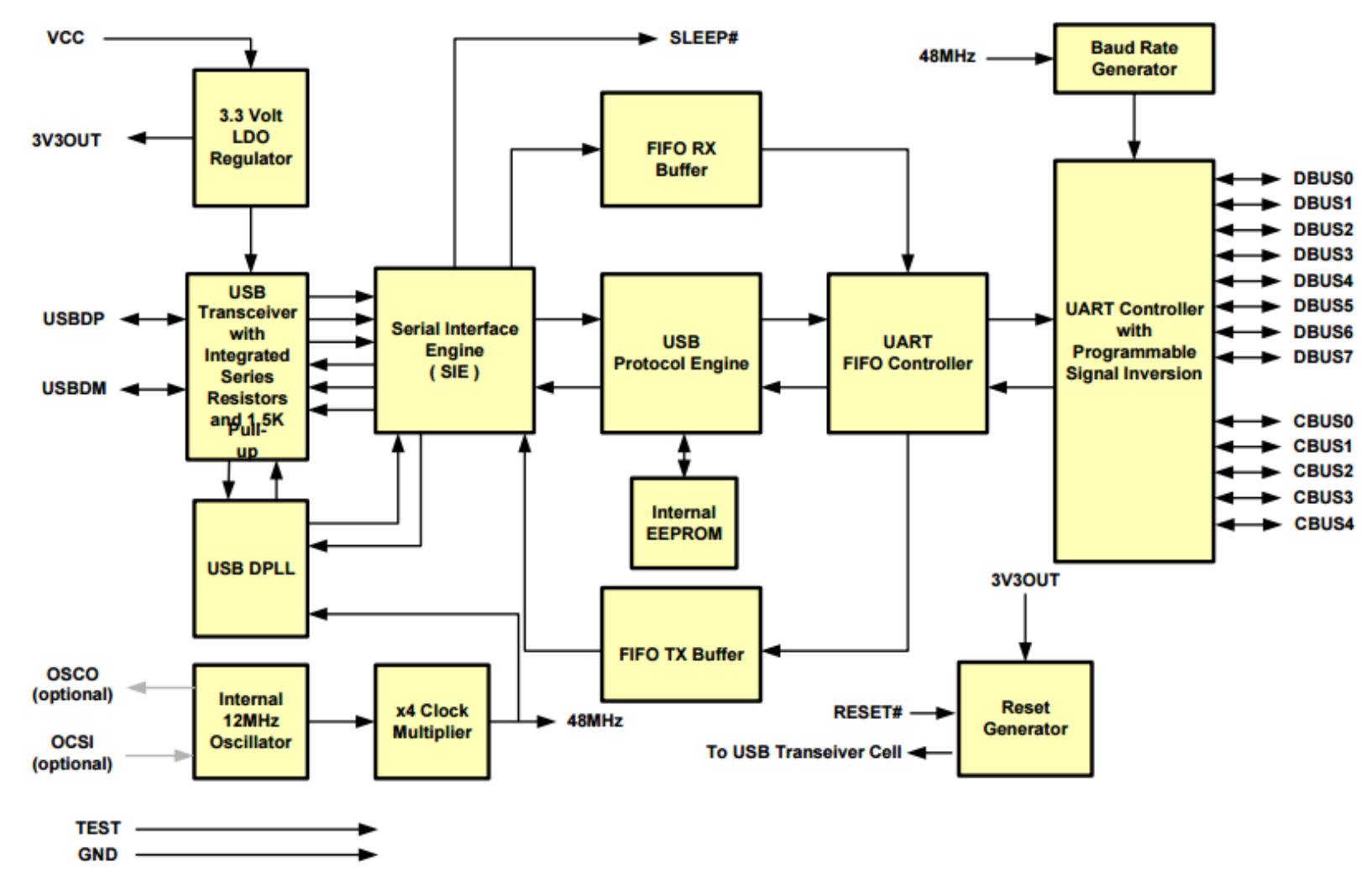

Figure 7. FTDI 232RL operational block diagram (FTDI).

For the design of the TEG-powered WSN, both the FTDI interface with USB and a standard pass through interface are included to ensure any kind of connectivity with a serial device. Figure 8 shows the schematic diagram of the final component design of the USB interfacing used in the design of TEGpowered WSN. Observe in Figure 8, there are a couple of jumpers which enables back feeding 5V TTL USB power into the board and provisions powering from outside USB devices such as typically seen by USB On-the-Go.

\subsubsection{Real-Time Clock}

The real-time clock was chosen to have the ability to date- and time-stamp collected data. Initially, the real-time clock MAXIM DS1307 was used but later dropped because it needed 5V power externally which would have been hard to get efficiently using both low- and high-powered TEGs. In addition, the DS1307 required excessive external components and lacked accuracy. Instead, the real-time clock MAXIM DS3231 is used for time and date stamping and has an accuracy of up to $3 \mathrm{ppm} /$ year. DS3231 also supports a simple to use I2C interface using the fast transmission rate of $400 \mathrm{kHz}$. There is also an option to include a battery backup. The backup is important to ensure timekeeping information is not lost 


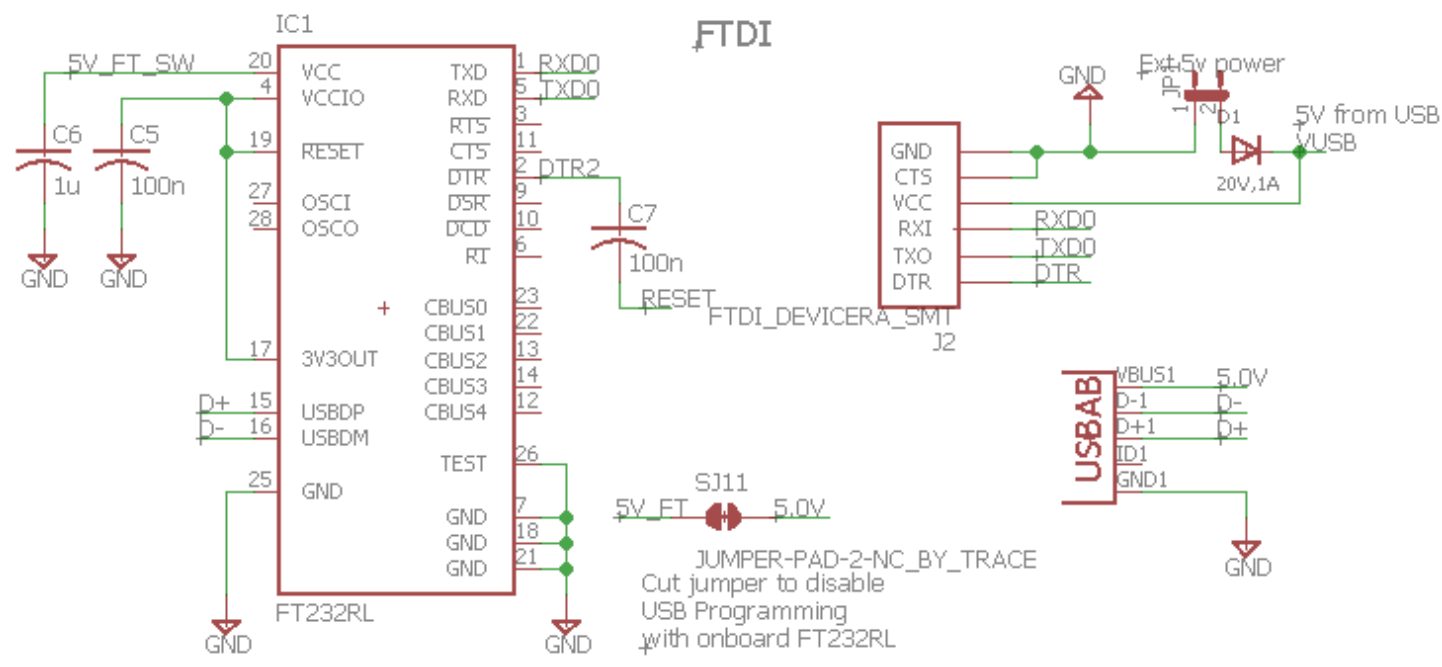

Figure 8. FTDI 232RL schematic (FTDI).

when one WSN is replaced for another WSN or when the power required to operate the WSN drops below the operating limit, thereby not losing the timekeeping on events. Figure 9 shows the schematic implementation of the DS3231, with its associated components. Figure 10 shows the DS3231's internal block-diagram for further understanding of the inner workings and layout of the device. The DS3231 requires very limited external parts, reducing the possibility of any inaccuracy due to external processes. To properly initialize the real-time clock, software drivers were coded by taking to consideration following attributes:

1) Device Initialization:

a) Enable write to the DS3231

b) Enable the internal oscillator

c) Enable hardware interrupts

2) Instantiate write register to the DS3231

3) Check for oscillator stop flag conditions

4) Load counter values

5) Synchronize clock

For further control over the real-time clock and easier user interaction with the device, macros are created to control the devices.

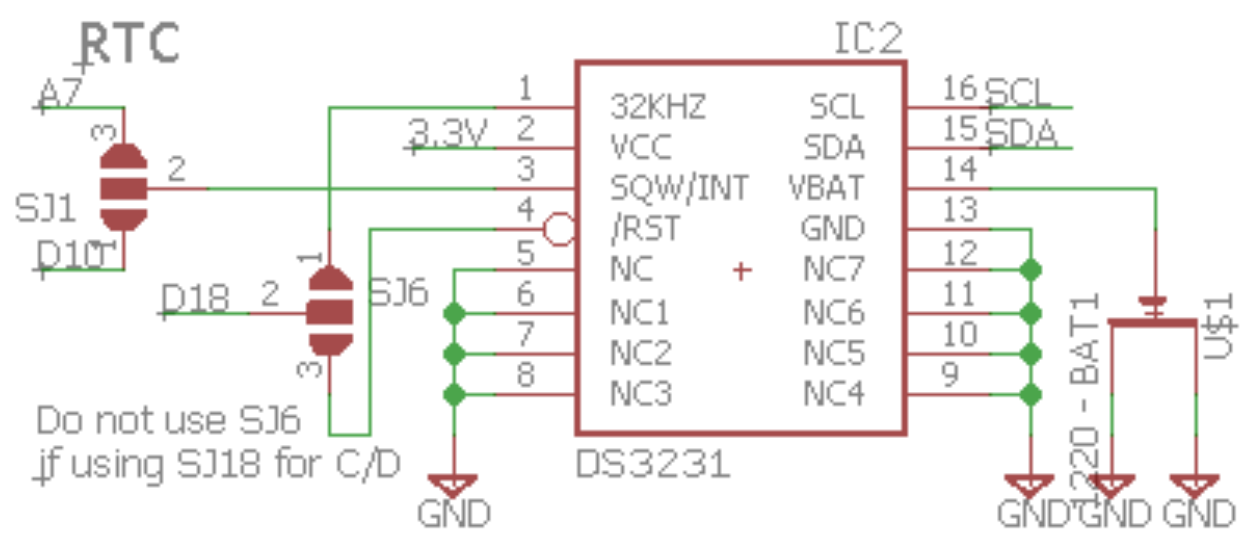

Figure 9. MAXIM DS3231 Real-Time Clock schematic (DS3231). 


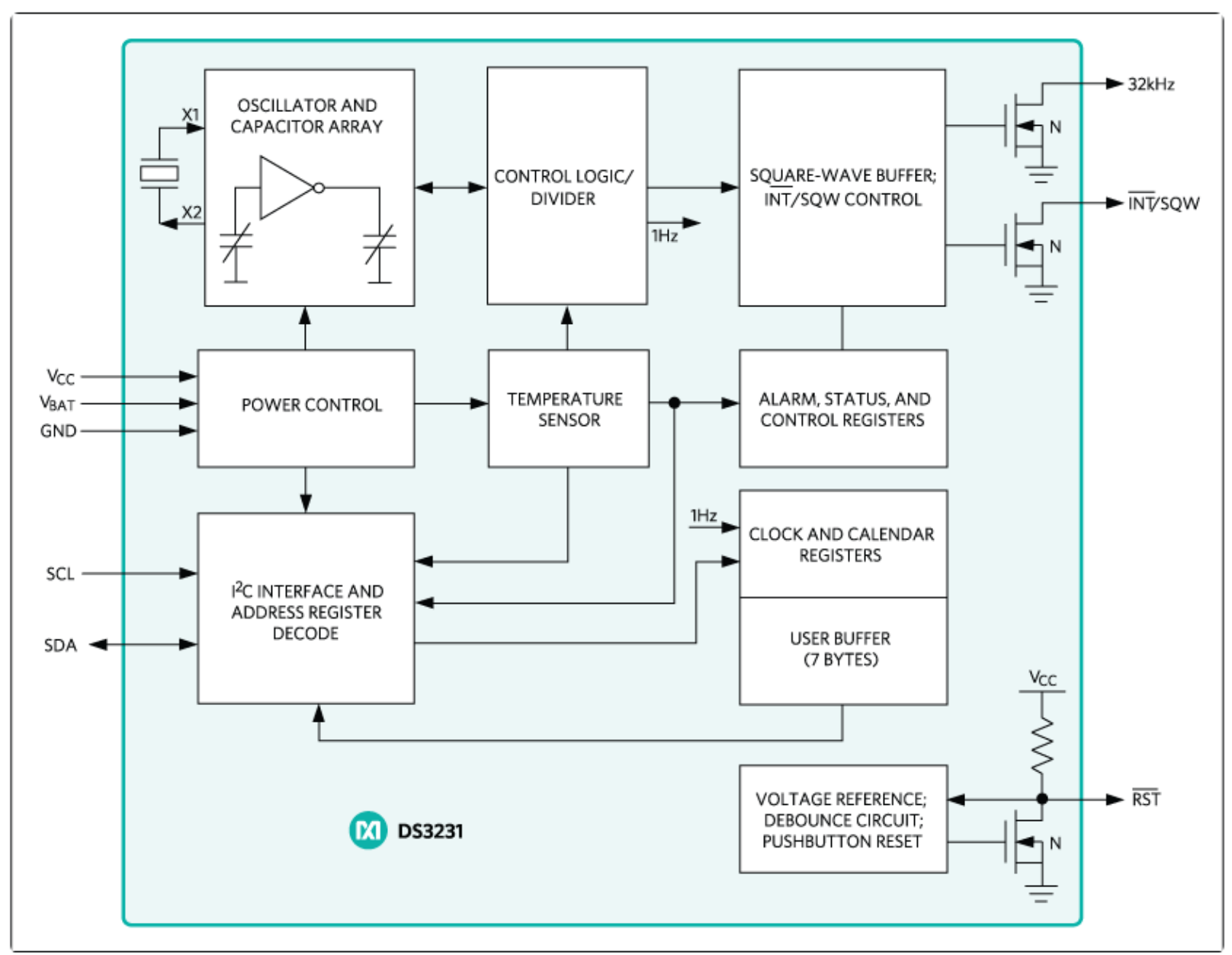

Figure 10. MAXIM DS3231 Operational block diagram (DS3231).

\subsubsection{Micro-Storage Device (SD)}

The data storage interface for the sensor node design is a micro-SD card. By embedding a micro-SD card onto the sensor node, a backup of time-stamped data (from the real-time clock) can be stored on the physical device. This is good because in a case where the wireless communication system goes down, there is also a hard-copy of the data being stored. The micro-SD port is a standard transflash port which can be found on nearly every device. Along with the micro-SD port is the Serial Peripheral Interface (SPI) port to allow for expansion of the micro-SD port. Figure 11 shows the SD card port along with the SPI port. With the integrated card-detection pins on the chosen micro-SD port, it is possible to program the system in a manner which would disable the port to conserve even the smallest bit of power and poll less frequently for a card. The SPI header present in the schematic allows for additional micro-SDs to be plugged-in as part of memory expansion. The steps followed to initialize the micro-SD device are shown in Figure 12. Flow-chart summarizing steps required to initialize Micro-SD.

. Once the micro-SD card is initialized, a set of necessary commands required to set the level of power to be consumed by the devices on the sensor node were determined. 


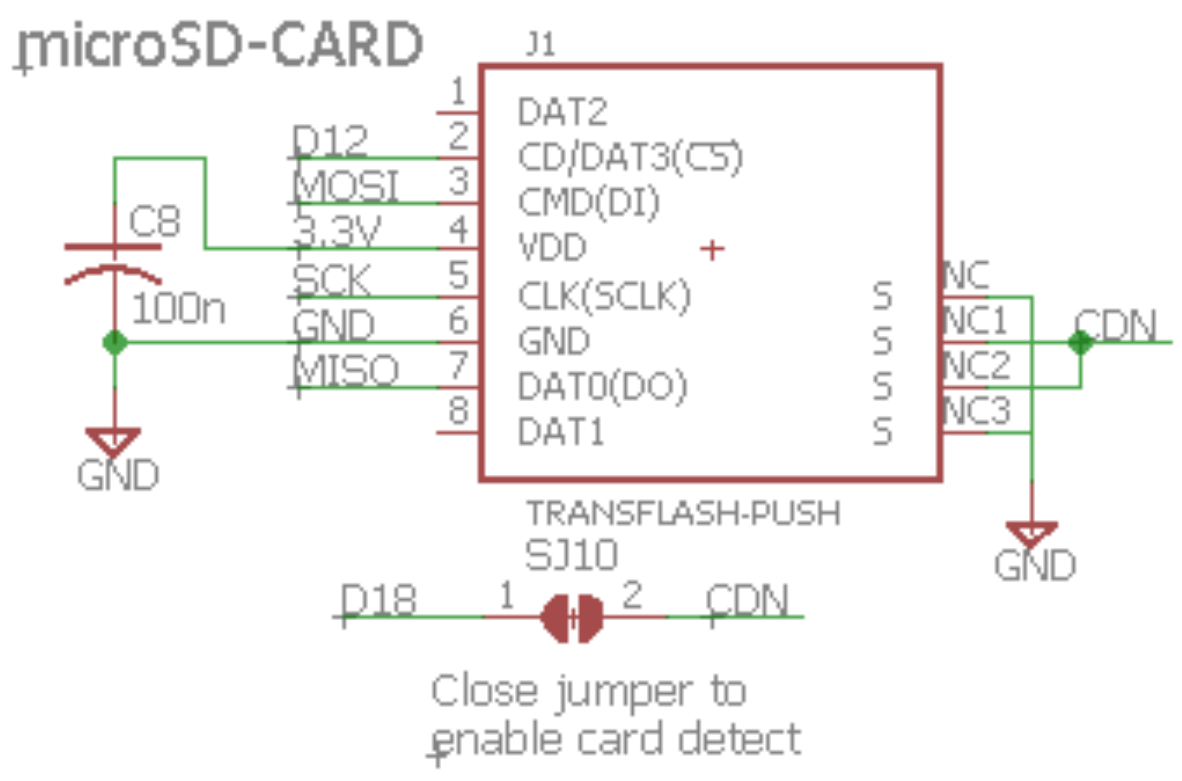

\section{microSD/SPI HEADER}

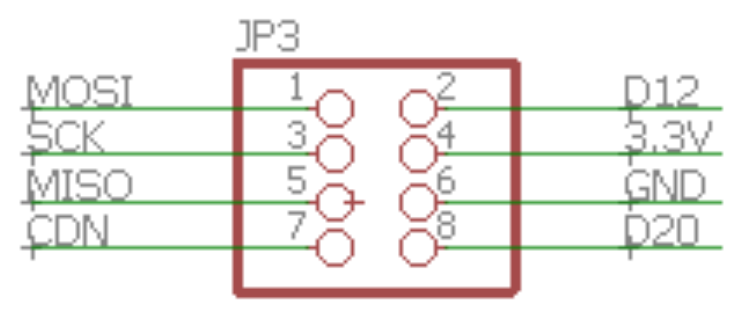

Figure 11. Micro-SD schematic.

\subsection{Wireless Transmission}

Different wireless communication protocols were evaluated. Due to the high power consumption of the IEEE 801.11 communication protocol, the IEEE 802.15.4 communication protocol was selected for implementation in the sensor node.

Research into ISA100 and Mi-Wi showed pretty quickly that those chips have become obsolete and not used very often. Thread is a fairly new protocol that seems to still be in the development stage but is developing a large umbrella of companies it works with such as Samsung, Bosch, Verizon, and several others. Wireless HART is probably the industry leader when it comes to large process automation systems for factories and various manufacturing systems. Wireless HART is proprietary and expensive because one would have to work directly with the company to implement any of its technology. Zigbee has made several versions of their 'XBee' chipset over the years and has become a standard. XBee chips are very affordable and one can communicate with the transceivers through common serial protocols. Due to the commercial availability of the transceivers and the fact that the XBee modules are relatively easy to interface, Zigbee/XBee protocol and chipset were selected for implementation. 


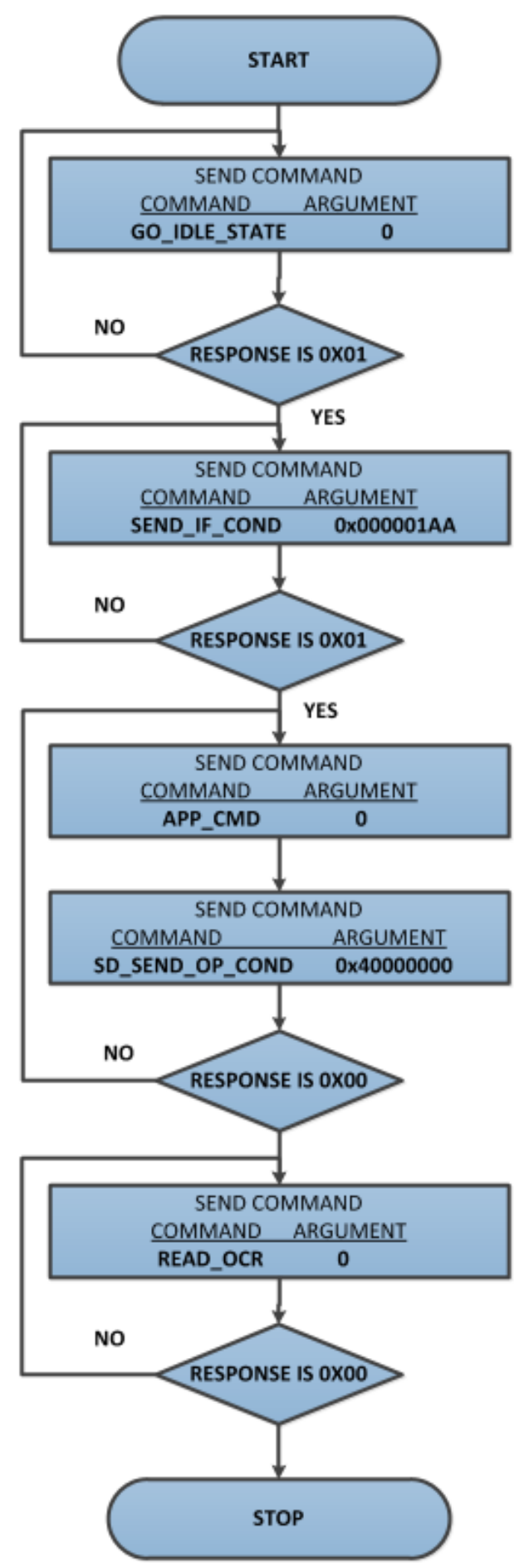

Figure 12. Flow-chart summarizing steps required to initialize Micro-SD.

\subsubsection{ZigBee/XBee}

Interfacing with the XBee module through the Universal asynchronous receiver-transmitter (UART) was implemented. Figure 13 shows an example of data flow from one microcontroller utilizing an XBee transceiver/receiver to another microcontroller using an XBee transceiver/receiver. The four important 
signals used in the UART protocol are data in (DIN), data out (DO), request to send (RTS), and clear to send (CTS). The data flow in our design will be similar to this schematic. Currently, there are three versions of the XBee wireless transceiver: XBee, XBee Pro-SB, and XBee Pro SB2. Table 2 below breaks down a few important specifications of the different versions. They all have the same idle current $(15 \mathrm{~mA})$ and similar size; but the main differences are seen in the transmit output power, and transmission range. Due to the higher transmission output power, longer distance, and lower operating current, the XBee Pro SB2 was selected and implemented on to the board.

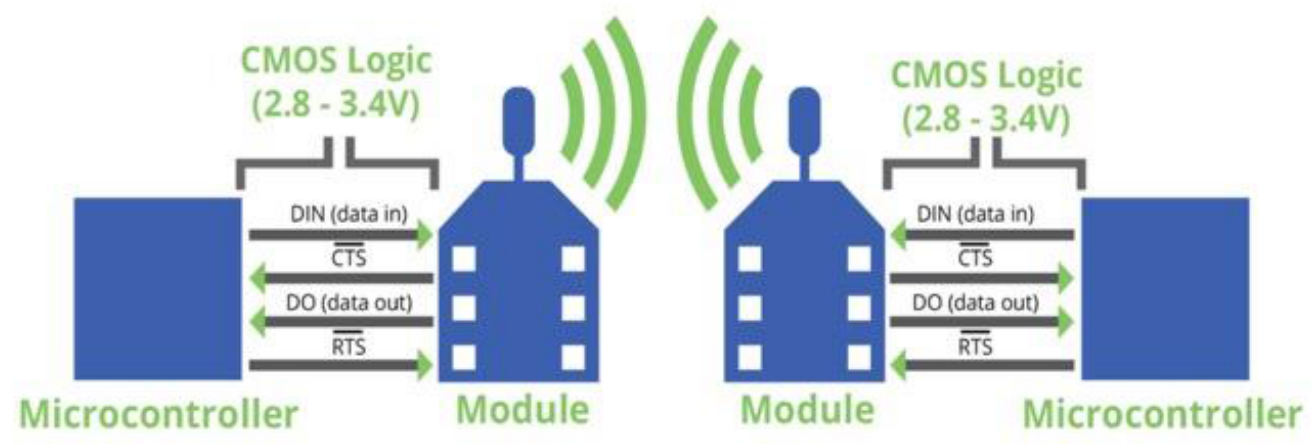

Figure 13. Typical UART data flow schematic.

Table 2. Major specifications of three XBee modules.

\begin{tabular}{|c|c|c|c|}
\hline Specification & XBee & XBee-Pro (SB) & Xhee-Pro (SB2) \\
\hline Indoor/urban range & Up to $133 \mathrm{ft} .(40 \mathrm{~m})$ & Up to $300 \mathrm{ft} .(90 \mathrm{~m})$ & Up to $300 \mathrm{ft} .(90 \mathrm{~m})$ \\
\hline $\begin{array}{l}\text { Outdoor RF line-of-sight } \\
\text { range }\end{array}$ & Up to $400 \mathrm{ft} .(120 \mathrm{~m})$ & Up to 2 miles $(3200 \mathrm{~m})$ & Up to 2 miles ( $3200 \mathrm{~m}$ ) \\
\hline Transmit power output & $2 m W(+3 d B m)$ & $50 \mathrm{~mW}(+17 \mathrm{dBm})$ & $63 \mathrm{~mW}(+18 \mathrm{dBm})$ \\
\hline Supply voltage & $2.1-3.6 \mathrm{~V}$ & $3.0-3.4 \mathrm{~V}$ & $2.7-3.6 \mathrm{~V}$ \\
\hline $\begin{array}{l}\text { Operating current (transmit, } \\
\text { max output power) }\end{array}$ & 40mA (@3.3V) & 295mA (@3.3V) & 205-220mA (@3.3V) \\
\hline Idle current & $15 \mathrm{~mA}$ & $15 \mathrm{~mA}$ & $15 \mathrm{~mA}$ \\
\hline Dimensions & $0.960^{\prime \prime} \times 1.087^{\prime \prime}$ & $0.960^{\prime \prime} \times 1.297^{\prime \prime}$ & $0.960^{\prime \prime} \times 1.297^{\prime \prime}$ \\
\hline I/O interface & $\begin{array}{l}\text { 3.3V CMOS UART (not } \\
5 \mathrm{~V} \text { tolerant), DIO, ADC }\end{array}$ & $\begin{array}{l}3.3 \mathrm{~V} \text { CMOS UART (not } \\
5 \mathrm{~V} \text { tolerant), DIO, ADC }\end{array}$ & $\begin{array}{l}3.3 \mathrm{~V} \text { CMOS UART (not } 5 \mathrm{~V} \\
\text { tolerant), DIO, ADC }\end{array}$ \\
\hline
\end{tabular}

For this research, two analog temperature measurements from thermocouples were recorded and digitized and passed to microcontroller. The microcontroller will timestamp and send data to the on-board data storage and to the XBee transceiver for transmission through UART. Once the XBee is ready to send, it will send the two timestamped temperature pieces of data to a laptop or desktop computer which is interfacing with another XBee module. Figure 14 depicts this data flow in a general schematic. 

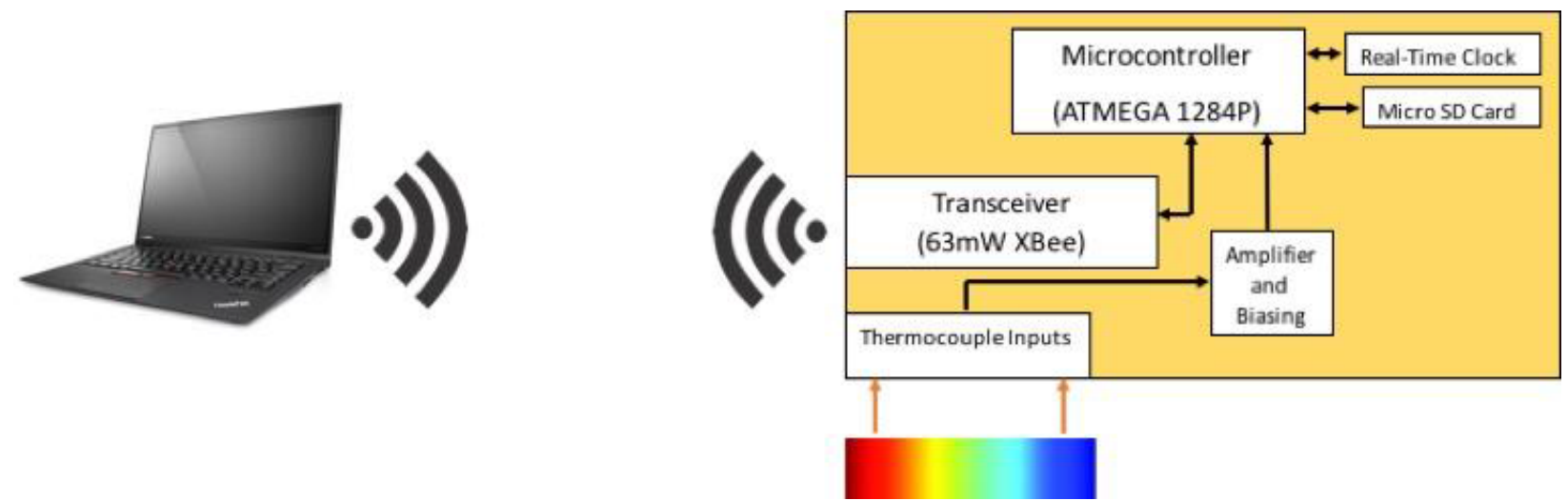

Figure 14. Initial data flow design schematic for wireless communication.

\subsection{Sensing Inputs}

Since this sensor node responseds to physical or environmental conditions, application-specific sensor inputs are built into the circuit board and can be expand upon application requirements.

\subsubsection{Thermocouple Inputs}

For this design, thermocouple inputs were implemented on the circuit board. Thermocouples are specialized temperature sensing devices which generate a very small voltage in response to a temperature present on a bimetallic probe. Thus, specialized connectors are being used on the sensor node which are provided by manufacturer. They are very small in size and can be implemented in a space-efficient manner.

\subsubsection{Amplifier/Biasing (MAX)}

The outputs of the thermocouple socket go into a specialized amplifier designed for thermocouples. The amplifier is a MAXIM MAX31856 which is used in conjunction with the specialized thermocouple sockets. Figure 15 shows the MAX31856 schematic.

The MAX31856 was chosen for its high accuracy of $0.15 \%$ linearity errors, $0.7 \mathrm{C}$ cold-junction accuracy, and 19-bit built-in ADC resolution [MAX31856]. Additional features which made the MAX31856 stand out above the rest are its fault tolerance and detection circuitry. The MAX31856 is able to detect broken/open thermocouples as well as detect over- and under-temperature faults which may result from running an incorrectly rated thermocouple for a temperature sensing application. Figure 15 shows those fault LEDs which, when enabled by the solder jumpers, show a visible sign that a fault was detected. If there is no LED connected, it is possible to configure the MAX31856's internal interface to send an error code to a remote user when one of the faults occurs and is detected. The code for the thermocouple amplifiers can be based on a set of definitions that determine the low-level operations supported by the MAX31856.

\subsubsection{SPI and UART}

The microcontroller in use has several inputs and outputs which are not actively used. Figure 16 shows the schematic representation of two header-ports which are included in the circuit design. These ports allow for additional sensors or usage of built in ADC operations through standard communications protocols such as: SPI, I2C, and UART. An example of some sensors that could be added are: barometric pressure, humidity, light, noise, radiation, etc. 

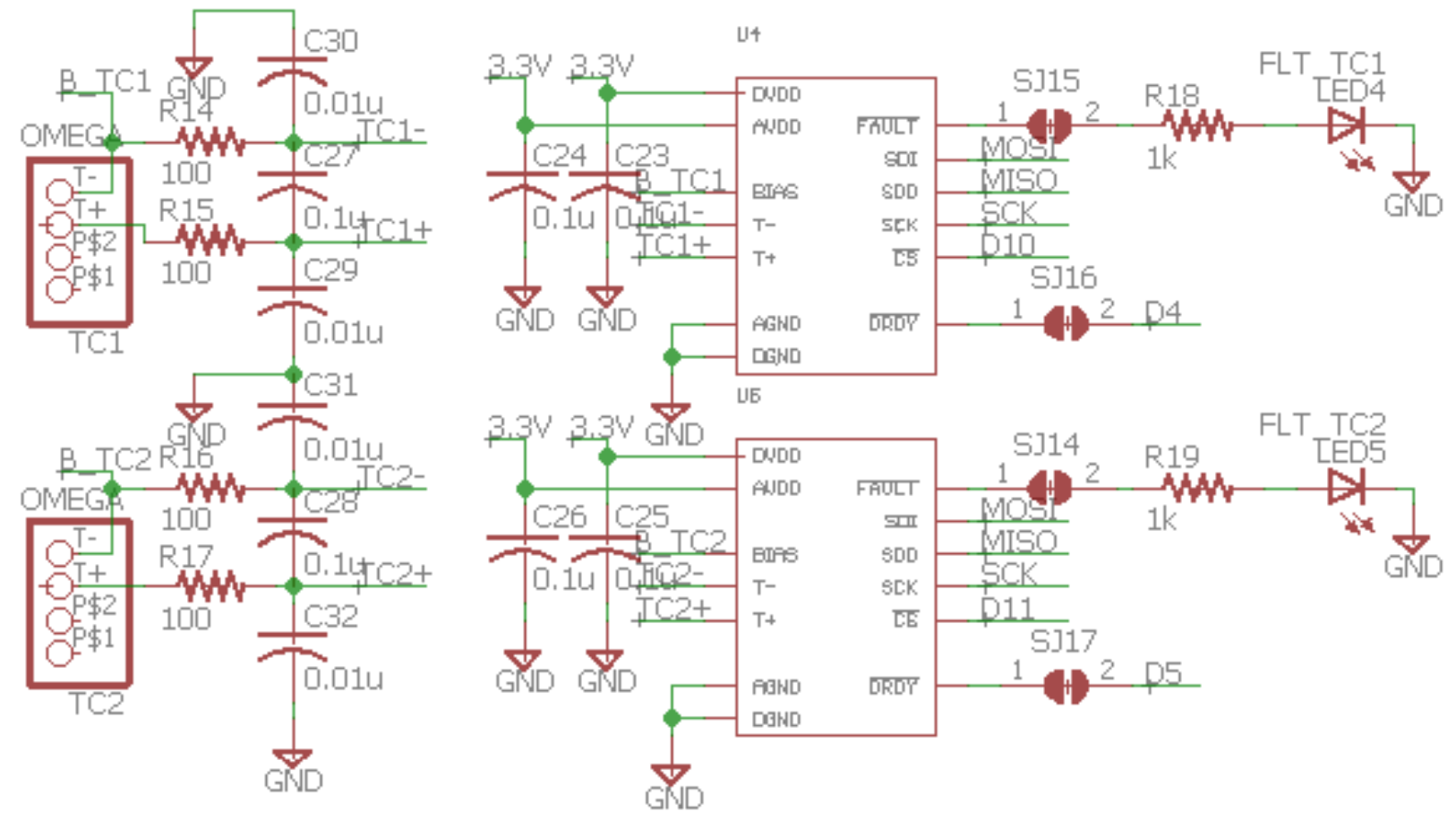

Figure 15. Thermocouple and MAXIM MAX31856 thermocouple amplifier schematic.

\section{HEADERS}
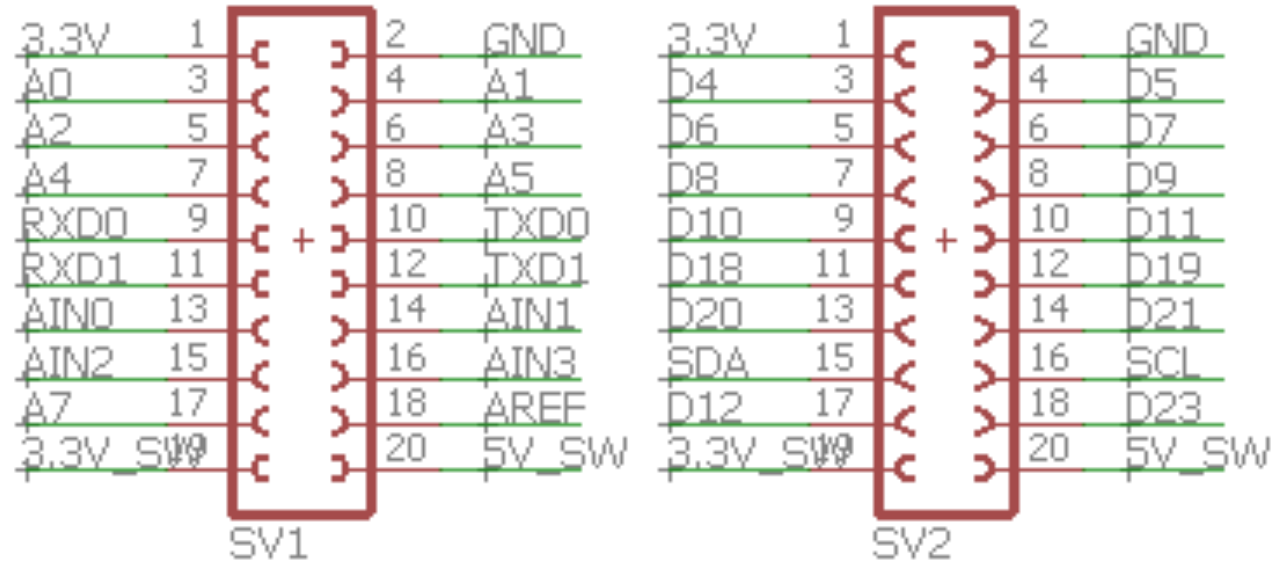

Figure 16. Header ports schematic.

\section{TEG-POWERED WSN PROTOTYPE}

Based on the discussions on selection of each elements of the TEG-powered WSN architecture, Figure 17 shows the prototype of the TEG-powered WSN board developed and tested in this project. 


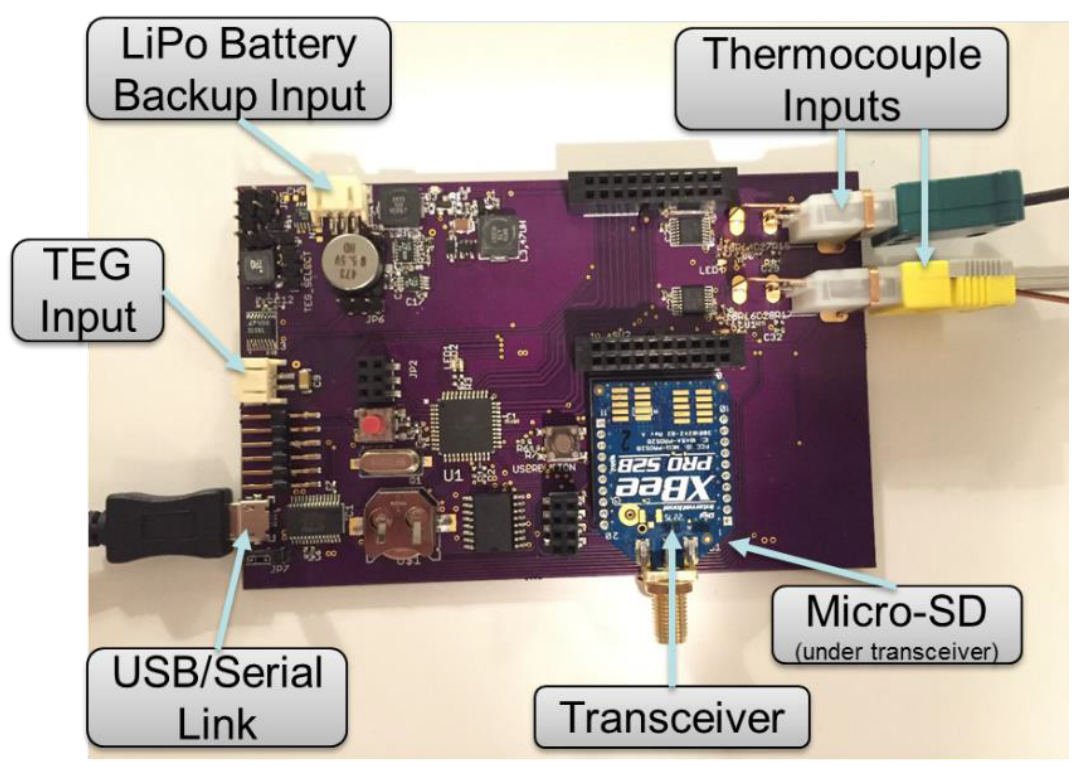

Figure 17. TEG-powered WSN prototype.

In this design, a 2-layer printed circuit board was chosen for a fast turnaround time to ensure functionality of the component selection and to show a proof of concept. All aspects of the power and communication system were implemented on the first revision. However, the main drawback of the design (shown in Figure 17) was its large size needed to accommodate the necessary signal traces on the 2-layer printed circuit board. The routing was inefficient, but was functional.

The results from the power management system are in relation to the system's ability to produce a relatively constant $3.3 \mathrm{~V}$ output to the rest of the communication system in order to ensure successful data capture and transmission. The input voltage from the benchtop power supply connected to the TEG was varied. The time between transmissions and the input voltage were varied in order to produce the relationship in the Figure 18.

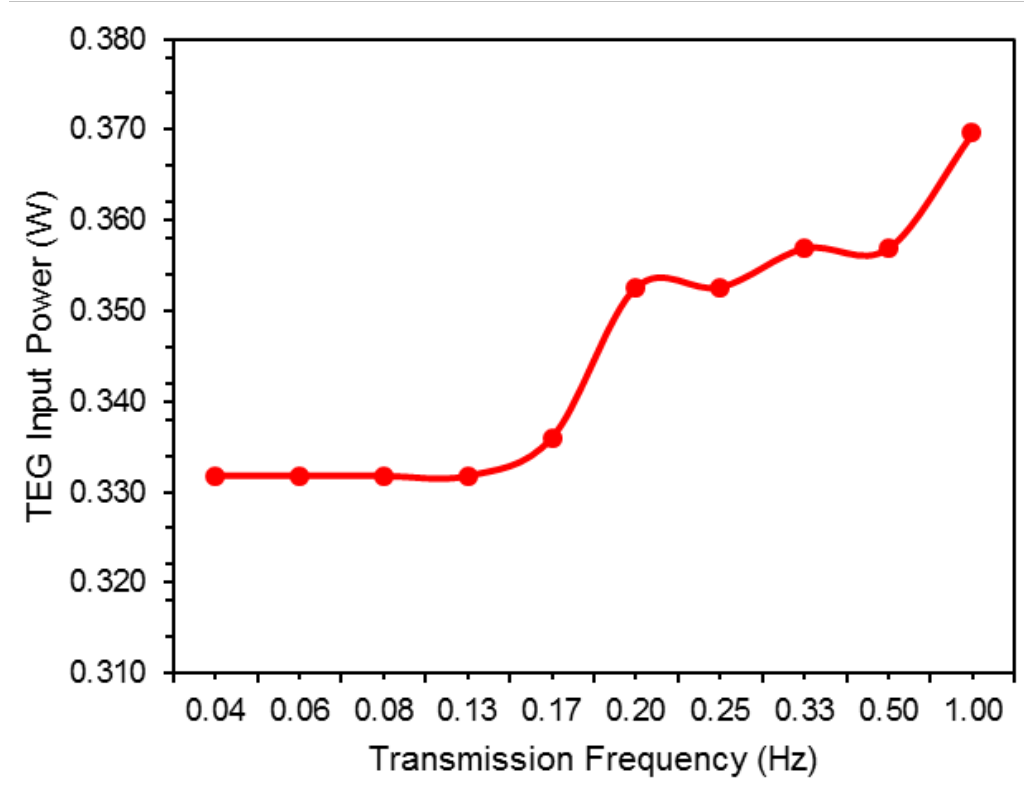

Figure 18. TEG input power versus frequency of transmission. 


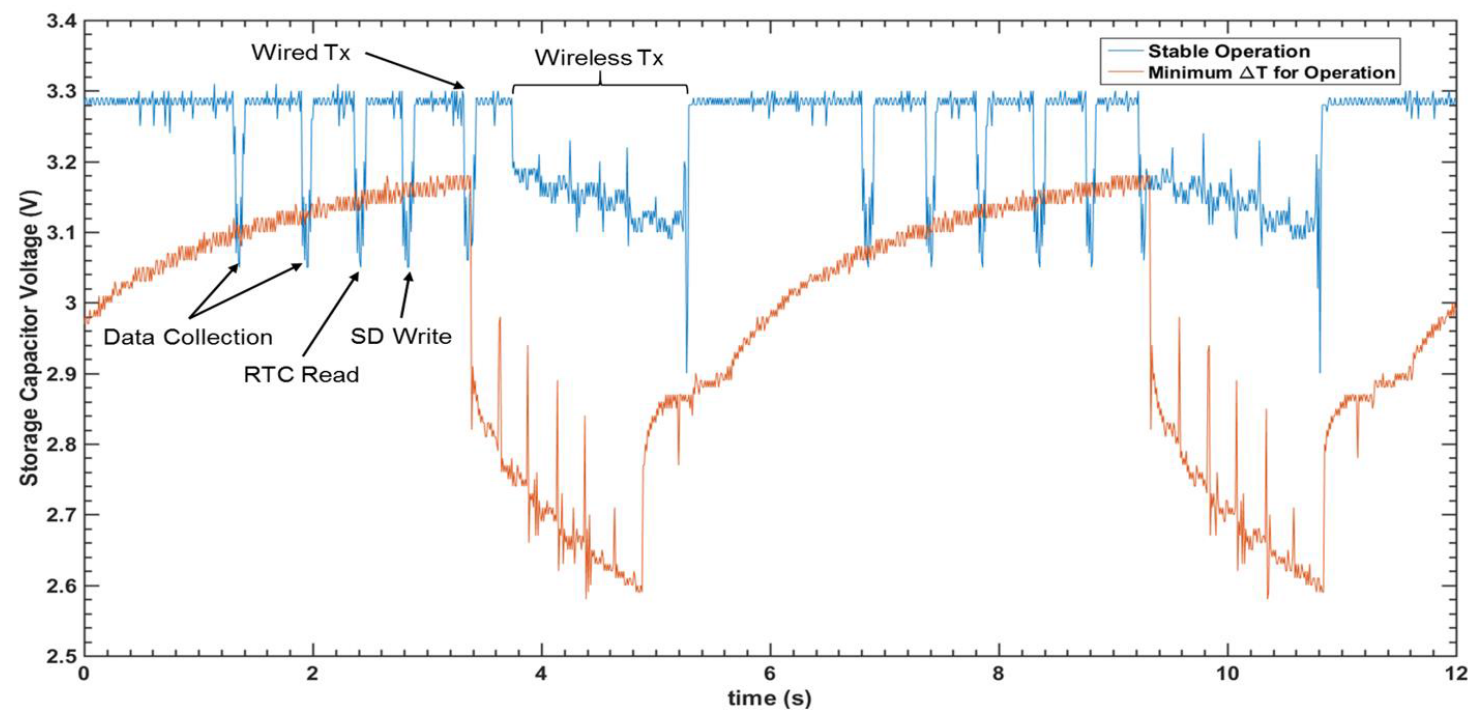

Figure 19. Power system output voltage during operation.

Three regions exist in this relationship. The first, for a frequency of transmission less than $0.13 \mathrm{~Hz}$, represents the minimum input voltage from the TEG is required for board operation. In order for the peripherals on the WSN to be powered between transmissions, $0.79 \mathrm{~V}$ on the input allows enough power to be stepped up to keep the systems running. The board cannot function with a lower input voltage than this with its current setup. The second region, between $0.13 \mathrm{~Hz}$ and $0.5 \mathrm{~Hz}$, represents a relatively linear relationship between the frequency of transmission and required power input from the TEG. As the frequency of transmission increases, more power is required from the TEG in order to charge the storage capacitor fast enough to ensure enough energy is available for subsequent transmission. Since the LTC3105 is continuously operating at its maximum current rating, a higher input voltage with the same current results in more power for the system. The final and third region, between $0.5 \mathrm{~Hz}$ and $1 \mathrm{~Hz}$ and beyond, represents the current speed limitations for the WSN. At this frequency, the microcontroller is executing its code as quickly as possible.

One possible solution to alleviate this speed limitation involves either overclocking the processor, or using an inherently quicker/more efficient processor. This would allow the code to execute more quickly, and increase how often the WSN can transmit its sensor data. However, this comes at the expense of requiring more power from the TEG. Figure 19 shows the waveform capture of the power management system during operation.

Figure 19 contains two waveforms, each from a different TEG input voltage. The blue waveform is the system operating at approximately $0.88 \mathrm{~V}$, delivering plenty of power from the TEG to charge the input capacitor rapidly. The data collection and processing actions taking place can be seen as output voltage dips, as well as the wireless transmission. The orange waveform is a much lower TEG input of around $0.79 \mathrm{~V}$. Here, the characteristic resistor capacitor curve for the storage capacitor is evident as it recharges, as well as the energy depletion during the wireless transmission. This data was captured while using the half-heusler $(\mathrm{HH})$-module TEG that requires a much higher $\Delta \mathrm{T}$, but also consequently has a lower internal resistance.

The internal resistance of the modules used presented a difficulty during testing. If the internal resistance of the module was too high, the TEG voltage output would vary greatly. During testing, the Marlow bismuth-telluride (BiTe) module would vary as much as $1 \mathrm{~V}$ under load from the WSN when the board was transitioning between steady state and recovering from transmission. As the MPPT was tuned to draw maximum power from the TEG at the loaded-down voltage of approximately $0.88 \mathrm{~V}$ while the system was recovering from transmission, the $1 \mathrm{~V}$ increase after charging would move the TEG voltage 
outside of the tuned MPPT curve, resulting in less power being recovered. The HH-module, with its lower internal resistance, greatly reduced this issue.

The module selection is also determined by the temperatures the system is expected to witness. With the Marlow TEG, the WSN was able to function as expected with as little as a $40^{\circ} \mathrm{C} \Delta \mathrm{T}$. This was demonstrated by heating the hot side of the module to approximately $70^{\circ} \mathrm{C}$, while keeping the cold side of the module close to room temperature. The HH-module, however, required a much larger $\Delta \mathrm{T}$ to produce the same power. Here the hot side needed to be around $450^{\circ} \mathrm{C}$ with room temperature on the cold side.

The results of the communications system testing show that the system works properly. In testing with the low power XBee module ( $2 \mathrm{~mW}$ antenna), a range of approximately $180 \mathrm{ft}$ was able to be measured in a non-line-of-sight, indoor environment. In a line-of-sight, outdoor environment, a maximum range of $1000 \mathrm{ft}$ was able to be validated. A different transceiver module was purchased for testing but, after seeing the results of power management testing, that module would not have been able to be powered properly. The $2 \mathrm{~mW}$ antenna module consumed approximately 0.132 Watts of power during transmissions and between transmissions was allowed to go into an idle state which consumed less power.

A major design aspect while coding and programming the device was redundancy. For this, the data transmitted by the transceiver is stored both to a computer and to a micro-SD card. The micro-SD card uses the FAT32 filesystem to enable compatibility among a broad range of devices, and enables future storage of different types of files or commands to be referenced by the WSN.

The time- and date-stamping features of this WSN are very important for all data collected, as it allows a user in the future to examine the data collected and draw conclusions about operating conditions present because those conditions can vary widely.

\section{VALIDATION OF MATHEMATICAL MODELING}

A detailed and rigorous mathematical model capturing different operational states of a WSN and associated interaction at the node and network level was developed in (Agarwal et al., 2017). The details are not presented here, as they are not the scope of this report. However, the technical specifications of the different components used to develop a TEG-powered WSN are utilized to validate the mathematical model that was previously validated via simulation-based analysis. The model parameters used to compute expected energy consumed by a WSN (shown in Figure 20) at different event detection probabilities $(\alpha, \beta)$ for different duty-cycle $(d)$ are summarized in Table 3 . The validation exercise shows that the model developed is conservative in estimating the power required by a WSN under different operating conditions. Comparing Figure 18 and Figure 20, it is clear that maximum power estimated using the model for highest duty-cycle of operation is still below the lowest TEG power output.

Table 3. The expected value and the variance of the energy a WSN spends in each state.

\begin{tabular}{|c|l|c|l|}
\hline \multicolumn{1}{|l|}{ Parameter } & Value & Parameter & Value \\
\hline$P_{0}$ & $0.4620 \mathrm{~mW}$ & $E_{t r 1}$ & $0.018 \mathrm{~mJ}$ \\
\hline$P_{1 i}$ & $10.51 \mathrm{~mW}$ & $E_{t r 2}$ & $0.038 \mathrm{~mJ}$ \\
\hline$P_{1 r}$ & $45 \mathrm{~mW}$ & $P_{1 e}$ & $26.77 \mathrm{~mW}$ \\
\hline$P_{2}$ & $24.15 \mathrm{~mW}$ & $P_{3}$ & $49.51 \mathrm{~mW}$ \\
\hline$R$ & $11 \mathrm{Mbps}$ & $L$ & $1024 \mathrm{bits}$ \\
\hline$\alpha, \beta$ & {$[0,1]$} & $d$ & {$[0,1]$} \\
\hline
\end{tabular}




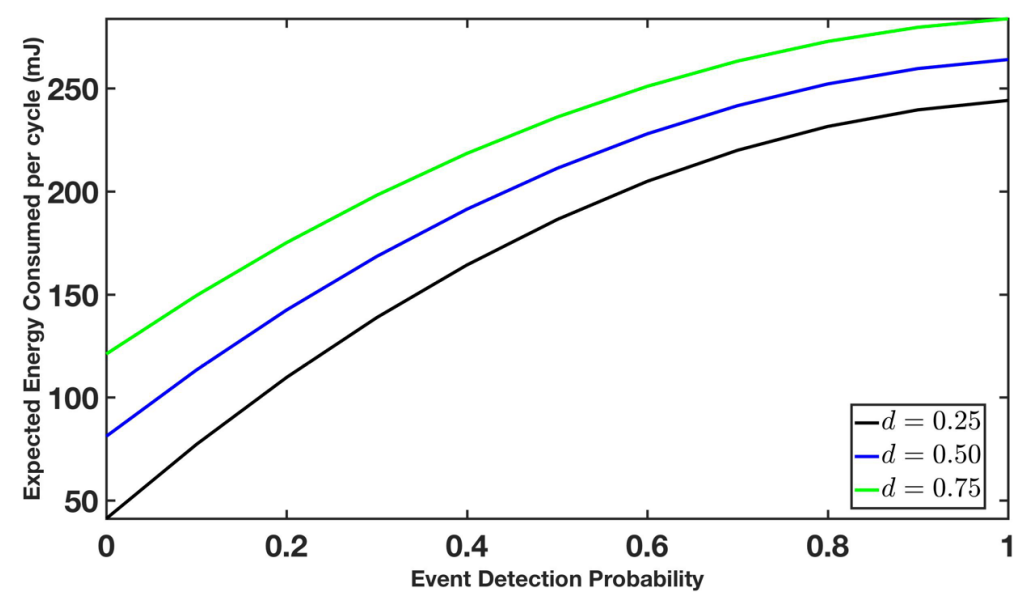

Figure 20. WSN model output based on prototype data.

\section{CONCLUSIONS AND FUTURE WORK}

A thorough design of a WSN which is powered by a TEG has been presented here. The embedded design leverages a microcontroller from the trusted ATMEL family. The power management system which interfaces with the TEG has been designed to accommodate a variety of input voltage levels. The power management system also uses a number of ICs from Linear Technologies, an industry leader in analog circuit design. The power management system also integrates a battery backup system, so that if the TEG were to fail the sensor could still run for a significant amount of time ( 25 hours). The wireless communications system consists of an XBee transceiver/receiver implementing the IEEE 802.15.4 and Zigbee protocols. The design not only implemented the minimal functions required by our sponsor, but modularity was added so that several other sensing inputs using I2C, SPI, or UART could be fed into the microcontroller later. An extensive testing plan for both the power management system and the wireless communications system was presented. The cost of parts remained well within the budget and didn't exceed $10 \%$ of the total budget. Two printed circuit board versions of the wireless sensor node were produced and tested with a TEG.

The path forward would to be evaluate the technology readiness level for demonstration in an environment representative of a nuclear power plant with varying thermal heat.

\section{REFERENCES}

Agarwal, V., 2011, "Foundation for power management in battery powered interconnected wireless sensor networks," Ph.D. Thesis, Purdue University, West Lafayette.

Agarwal, V., R. A. DeCarlo, L. H. Tsoukalas, 2017, "Modeling energy consumption and lifetime of a wireless sensor node operating on a contention-based MAC protocol," IEEE Sensors Journal, 17.6, pp. 5153-5168.

Atmega: http://www.atmel.com/ru/ru/Images/doc8059.pdf

Akyildiz, I. F., W. Su, Y. Sankarasubramanian, and E. Cayirci, 2002, “A survey on sensor networks,” IEEE Communication Magazine 40.8, pp. 102-114.

Beeby, S. P., M. J. Tudor, and N. M. White, 2007, "Energy harvesting vibration sources for microsystems applications," Measurement Science and Technology 14.2, pp.70-87.

Clayton, D.A., W.H.J Andrews and R. Lenarduzzi, 2012, Power Harvesting Practices and Technology Gaps for Sensor Networks, ORNL/TM-2012/442, Oak Ridge National Laboratory, September 2012. 
Culler, D., D. Estrin, and M. Srivastava, 2004, "Guest editor's introduction: An overview of sensor networks," Computer 37 pp.41-49.

Dietrich I. and F. Dressler, 2009, "On the lifetime of wireless sensor networks," ACM Trans. Sensor Networks 5.1, pp.1-39.

DS3231 RTC: https://datasheets.maximintegrated.com/en/ds/DS3231.pdf

FTDI 232RL: http://www.ftdichip.com/Support/Documents/DataSheets/ICs/DS_FT232R.pdf

Gilbert J. M. and F. Balouchi, 2008, “Comparison of energy harvesting systems for wireless sensor networks," International Journal of Automation and Computing 5.4, pp.334-347.

LTC3108: http://cds.linear.com/docs/en/datasheet/3108fc.pdf

LTC3105: http://cds.linear.com/docs/en/datasheet/3105fb.pdf

MAX31856 TC Amp: https://datasheets.maximintegrated.com/en/ds/MAX31856.pdf

ORNL, 2006, Assessment of Wireless Technologies and Their Application at Nuclear Facilities, NUREG/CR 6882, Oak Ridge National Laboratory, July 2006.

OMEGA TC Connectors: http://www.omega.com/temperature/pdf/PCC-OST-SMP.pdf

Poudel, B., Q. Hao, Y. Ma, Y. Lan, A. Minnich, B. Yu, X. Yan, D. Wang, A. Muto, D. Vashaee, X. Chen, J. Liu, M.S. Dresselhaus, G. Chen, and Z.F. Ren, 2008, "High-thermoelectric performance of nanostructured bismuth antimony telluride bulk alloys," Science 320, pp. 634-638.

Rabaey, J. M., M. J. Ammer, and J. L. da Silva, 2000, "PicoRadio supports ad hoc ultra-low power wireless networking," Computer 33pp. 42-48.

Raghunathan, V., S. Ganeriwal, and M. Srivastava, 2006, "Emerging techniques for long lived wireless sensor networks," Communication Magazine, 44: pp.108-114.

XBee Pro SB2: http://www.digi.com/resources/documentation/digidocs/PDFs/90000976.pdf

Zhang, Y., D. Butt, and V. Agarwal, 2015, "Nanostructured bulk thermoelectric generator for efficient power harvesting for self-powered sensor network," INL/EXT-15-36260, July. 